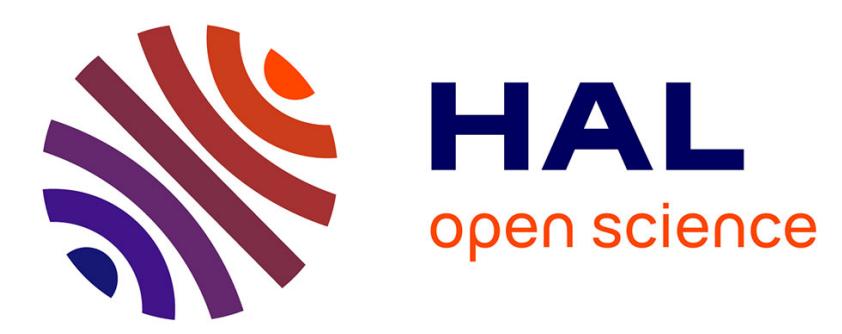

\title{
Bilateral control of interceptive saccades: evidence from the ipsipulsion of vertical saccades after caudal fastigial inactivation
}

\author{
Clara Bourrelly, Julie Quinet, Laurent Goffart
}

\section{- To cite this version:}

Clara Bourrelly, Julie Quinet, Laurent Goffart. Bilateral control of interceptive saccades: evidence from the ipsipulsion of vertical saccades after caudal fastigial inactivation. Journal of Neurophysiology, 2021, Control of movement, 125 (6), pp.2068-2083. 10.1152/jn.00037.2021 . hal-03168070v2

\section{HAL Id: hal-03168070 \\ https://hal.science/hal-03168070v2}

Submitted on 2 Apr 2021

HAL is a multi-disciplinary open access archive for the deposit and dissemination of scientific research documents, whether they are published or not. The documents may come from teaching and research institutions in France or abroad, or from public or private research centers.
L'archive ouverte pluridisciplinaire HAL, est destinée au dépôt et à la diffusion de documents scientifiques de niveau recherche, publiés ou non, émanant des établissements d'enseignement et de recherche français ou étrangers, des laboratoires publics ou privés. 
1 Bilateral control of interceptive saccades: evidence from

2 the ipsipulsion of vertical saccades after caudal fastigial

\section{inactivation}

4

Aix Marseille Université, Centre National de la Recherche Scientifique, Institut de Neurosciences de la Timone, Marseille, France.

Laurent Goffart : https://orcid.org/0000-0001-8767-1867

Julie Quinet : https://orcid.org/0000-0003-3043-3424

Title for running head: Neural control of interceptive saccades

*: C. Bourrelly and L. Goffart contributed equally to this work.

Address for correspondence:

Laurent Goffart, PhD,

E-mail: laurent.goffart@univ-amu.fr cedex 5, France. 


\section{Abstract (219 words $<=250$ words)}

22

23

The caudal fastigial nuclei (cFN) are the output nuclei by which the medio-posterior cerebellum influences the production of saccades toward a visual target. On the basis of the organization of their efferences to the premotor burst neurons and the bilateral control of saccades, the hypothesis was proposed that the same unbalanced activity accounts for the dysmetria of all saccades during cFN unilateral inactivation, regardless of whether the saccade is horizontal, oblique, or vertical. We further tested this hypothesis by studying, in two head-restrained macaques, the effects of unilaterally inactivating the caudal fastigial nucleus on saccades toward a target moving vertically with a constant, increasing or decreasing speed. After local muscimol injection, vertical saccades were deviated horizontally toward the injected side with a magnitude that increased with saccade size. The ipsipulsion indeed depended upon the tested target speed, but not its instantaneous value because it did not increase (decrease) when the target accelerated (decelerated). By subtracting the effect on contralesional horizontal saccades from the effect on ipsilesional ones, we found that the net bilateral effect on horizontal saccades was strongly correlated with the effect on vertical saccades. We explain how this correlation corroborates the bilateral hypothesis and provide arguments against the suggestion that the instantaneous saccade velocity would somehow be "encoded" by the discharge of Purkinje cells in the oculomotor vermis. 
41 Besides causing dysmetric horizontal saccades, unilateral inactivation of caudal fastigial 42 nucleus causes an ipsipulsion of vertical saccades. This study is the first to quantitatively 43 describe this ipsipulsion during saccades toward a moving target. By subtracting the effects on 44 contralesional (hypometric) and ipsilesional (hypermetric) horizontal saccades, we find that this 45 net bilateral effect is strongly correlated with the ipsipulsion of vertical saccades, corroborating 46 the suggestion that a common disorder affects all saccades. 


\section{Introduction}

Saccades are rapid changes in eye orientation whose time course is characterized by an interval during which the rotation speed increases to a maximum (acceleration) followed by an interval during which it returns to zero (deceleration). Starting with the eyes centered in the orbits, the changes in the contraction of lateral and medial recti muscles rotate the eyes horizontally whereas combined changes in the contraction of superior and inferior recti muscles, and the superior and inferior oblique muscles rotate them vertically (Robinson 1975). During vertical saccades, the tension in muscles involved in horizontal rotations exhibit a transient small reduction at the level of medial recti (Miller and Robins 1992). A burst of spikes from motoneurons causes the phasic contraction of agonist muscles while the relaxation of antagonist muscles is enabled by a pause of motoneurons which innervate them (Fuchs and Luschei 1970; Robinson 1970; Schiller 1970). Premotor commands for horizontal and vertical eye rotations originate in distinct regions of the reticular formation: burst neurons in the pontomedullary reticular formation drive horizontal saccades whereas those controlling vertical saccades are located in the rostral midbrain tegmentum (Fuchs et al. 1985; Hepp et al., 1989; Horn 2006; Moschovakis et al. 1996).

Robinson and Fuchs (2001) proposed that these populations of premotor neurons and the time course of saccades are under the control of neurons in the medio-posterior cerebellum: burst neurons in the contralateral caudal fastigial nucleus $(\mathrm{cFN})$ would support the acceleration of saccades while those in the ipsilateral cFN would help their deceleration. This biphasic pattern was suggested by the delay between the peaks of cFN discharge during contralateral and ipsilateral saccades (Fuchs et al. 1993; Ohtsuka and Noda 1991; Kleine et al. 2003). Moreover, after unilateral cFN inactivation, contralesional saccades are hypometric and exhibit lower peak velocity whereas ipsilesional saccades are hypermetric with a longer deceleration 
(Buzunov et al. 2013; Goffart et al. 2004). Thus, it was suggested that a shift of activity from the contralateral to the ipsilateral cFN would guide the trajectory of saccades (Optican 2005).

Numerous observations lead to questioning this isomorphism which was assumed between the brainstem activity and the kinematics of saccades. Firstly, Davis-Lopez de Carrizosa et al. (2011) showed that a model factoring muscle tension and its first derivative accounted for the firing rate of motoneurons better than a model factoring eye position and its first and second derivatives (velocity and acceleration). Secondly, the resemblance between the firing rate of premotor burst neurons and saccade instantaneous velocity (see for example Fig. 5B of Cromer and Waitzman (2007)) disappears when the spikes are not convolved with a Gaussian kernel (see Figs. 2 and 3 in Hu et al. (2007); Fig. 3C in Sparks \& Hu (2006) and Fig. 4 in van Gisbergen et al. (1981)). Thirdly, the inspection of cFN bursts reveals that the transition between the activity of the left and right $\mathrm{cFN}$ is not as sharp as the separation between the acceleration and deceleration phases. In fact, the bursts in the two nuclei largely overlap around the time of saccade peak velocity (Kleine et al. 2003). Moreover, some neurons burst after saccade onset during large contralateral head unrestrained gaze shifts, casting doubt on the cFN's role in accelerating saccades (Fuchs et al. 2010). Involvement in only decelerating ipsilateral saccades is also called into question by the changes in the acceleration of saccades after cFN inactivation (Buzunov et al. 2013; Quinet and Goffart 2007). Finally, a horizontal deviation (ipsipulsion) affects the full time course of vertical saccades, including both acceleration and deceleration, following unilateral cFN inactivation (Goffart et al. 2004; Iwamoto and Yoshida 2002; Quinet and Goffart 2007).

The hypothesis that $\mathrm{cFN}$ activity helps to accelerate contralateral horizontal saccades and to decelerate ipsilateral ones does not explain why vertical saccades exhibit this ipsipulsion. Robinson et al. (1993) proposed a different explanation: "during saccades to vertical targets, there is activity in the horizontal burst generator on one side that is not balanced by activity on 
the other. Such unbalanced activity might arise because in the normal animal, caudal fastigial neurons on each side burst at about the same time during vertical saccades". Emphasizing the organization of cFN efferences to premotor burst neurons (Sparks and Barton 1993) and the bilateral control of saccades (van Gisbergen et al. 1981), Goffart et al. (2004) went further by proposing that the unbalanced activity accounts for the dysmetria of all saccades during cFN unilateral inactivation, regardless of whether the saccade is horizontal, oblique, or vertical. According to this bilateral hypothesis, both $\mathrm{cFN}$ influence the premotor process, from saccade onset to saccade end. Regardless of its direction, the saccade is influenced by the discharge from both cFN. If the causes are the same, the ipsipulsion of vertical saccades should be correlated with the dysmetria of horizontal (ipsilesional and contralesional) saccades; this inference is not deducible from the scheme proposed by Robinson and Fuchs (2001). In the present study, we characterize the ipsipulsion of vertical saccades, and confirm this prediction using saccades toward a moving target as a probe. We investigated such saccades because they offer the methodological advantage of enabling to vary both target eccentricity and the saccade amplitude more easily than saccades toward static targets. Goffart et al. (2004) indeed found that the magnitude of the ipsipulsion increased when target eccentricity (see also Iwamoto and Yoshida 2002) or saccade duration increased. Which of these features (target eccentricity or saccade duration) determines the size of the horizontal error could not be determined from their data. Our results do not support a link between the ipsipulsion and saccade duration because across all our testing conditions, its magnitude was less frequently dependent upon the duration than upon the amplitude of vertical saccades. 


\section{Materials and Methods}

The materials and methods used in this work are identical to those described in Bourrelly et al. (2018a, b) and comply with the ARRIVE (Animal Research: Reporting of In Vivo Experiments) guidelines. We will remind them only briefly.

\section{Subjects and surgical procedures}

Two adult male rhesus monkeys (Macaca mulatta, 11-12 kg) participated in this study. Their eye movements were recorded with the electromagnetic induction technique. Training to the eye movement tasks started after full recovery ( $>1$ month after surgery). A craniotomy was made to permit the electrophysiological localization of saccade-related neurons in both fastigial nuclei. The surgical procedures and experiments were performed in accordance with the guidelines from the French Ministry of Agriculture and the European Community, after approval from the Regional Ethics Committee (authorization \# A13/01/13). Care and maintenance of animals were made under the auspices of a veterinarian and the assistance of animal facilities staff.

\section{Eye movement recording and visual stimulation}

During the experimental sessions, the monkeys were seated in a chair with their head restrained, facing a LCD video monitor (Samsung SyncMaster, P227f; 1,280 × 1,024 pixels, $100-\mathrm{Hz}$ refresh rate, $39 \times 29 \mathrm{~cm}$ ) located at a viewing distance of $38 \mathrm{~cm}$. The visual target was a Gaussian blurred white disk of $0.4^{\circ}$ diameter displayed over a gray background. Eye movements were measured with a phase-angle detection system (CNC Engineering, 3-ft. coil frame) and voltage signals encoding the horizontal and vertical positions of one eye were sampled at $500 \mathrm{~Hz}$. The triggering of stimuli, the on-line recording of the oculomotor performance and the data acquisition were controlled by a PC using the Beethoven software 
package (Ryklin Software). Eye position signals were calibrated by having the animal fixate stationary targets presented at $\pm 16^{\circ}$ along the horizontal or vertical meridians.

\section{Oculomotor tests}

The experiments were performed more than one year after the monkeys were tested and trained to make saccades toward moving targets (Quinet and Goffart 2015; Bourrelly et al. 2014, 2016). Each experiment consisted of several pre-injection (control) sessions and one postinjection session. During the control sessions, the eye movements were recorded with a series of trials performed over 3-4 successive days before the injection whereas the post-injection session consisted of recordings made during trials collected approximately 30-50 minutes after the muscimol was injected in the $\mathrm{cFN}$ (after removing the cannula from the brain and recording saccades toward static targets). Each trial started with a brief tone followed by the appearance of a target at the center of the visual display (straight ahead). After the monkey directed its gaze toward its location within a surrounding invisible window $\left(12^{\circ}\right.$ centered on the target $)$ and for a variable interval (ranging from 750 to $1500 \mathrm{~ms}$ by increments of $250 \mathrm{~ms}$ ), the central target moved centrifugally along a cardinal (horizontal and vertical meridians) or oblique axis with a constant speed $\left(10^{\circ} / \mathrm{s}\right.$ during $1,200 \mathrm{~ms}, 20 \%$ s during $600 \mathrm{~ms}$ or $40^{\circ} / \mathrm{s}$ during $\left.300 \mathrm{~ms}\right)$, or with an increasing (from 0 to $40 \%$ s during $600 \mathrm{~ms}$ ) or decreasing speed (from 40 to $0 \% \mathrm{~s}$ during $600 \mathrm{~ms}$ ). The different types of target speed were tested in separate blocks of trials. Within each block, the direction of target motion (cardinal or oblique) was pseudo-randomly selected (one out of eight possible directions) in order to prevent the generation of anticipatory eye movements. The monkeys' task was to track the target until the location where it disappeared at the end of the trial. The fixation constraints for controlling the accuracy of eye movements were relaxed with respect to requirements for obtaining their reward. Indeed, the monkeys had to direct their gaze within a large invisible window around the moving target $\left(12^{\circ}\right.$ centered on the moving target). Otherwise, the trial was aborted and a new trial started. Our recordings show that these relaxed 
constraints do not incite monkeys to perform inaccurate saccades (see Figs. 3, 5, 7 and 9 in Bourrelly et al. 2018; see also Fleuriet and Goffart 2012; Quinet and Goffart 2015). Each session (lasting 1 to 2 hours) was composed of different blocks of trials whose number depended upon the monkey's motivation. Water-deprived in their home cage, the monkeys obtained the water they need during daily sessions. A session ended when they stopped fixating the central target for more than ten successive trials.

\section{Muscimol injection}

A thin cannula (beveled tip) was connected to a Hamilton syringe with polyethylene tubing. We filled the inner volume with a saline solution of muscimol $(2 \mu \mathrm{g} / \mu \mathrm{l})$. The cannula was lowered through the same guide tube used during the electrophysiological sessions and aimed at the fastigial region where neurons emitted bursts during saccades. Small volumes $(0.2-$ $1.1 \mu \mathrm{l})$ of muscimol were injected by small pulses over a time interval of approximately 15 minutes. The injected volume was checked by the displacement of a meniscus of air in the tubing ( $1 \mathrm{~mm}$ corresponding to $0.1 \mu \mathrm{l}$ ). Before starting the recording of eye movements toward a moving target, saccades toward static targets were recorded for approximately 15-30 minutes in order to complete a companion study (Goffart et al. 2005, 2017b; Quinet and Goffart 2016). During the muscimol sessions, the blocks that tested the tracking of accelerating or decelerating targets were always the last ones.

\section{Data analysis}

The results presented in this paper concern the data obtained before and after ten unilateral muscimol injections performed in the cFN of two monkeys (6 injections in monkey A, 4 in monkey $\mathrm{Bi}$ ). For each experiment, the performance after muscimol injection was compared with that recorded during the 3-4 preceding control daily sessions. No noticeable difference was observed between the responses collected during the pre-injection sessions, so 
movements were pooled together to include some day-to-day variability in our control dataset. For each monkey, we injected muscimol into the left cFN in half of the experiments and in the right $\mathrm{cFN}$ in the others. All data were digitized on-line and analyzed off-line using a custommade software program that detected the onset and offset of the horizontal and vertical components of saccades on the basis of a velocity threshold $\left(30^{\circ} / \mathrm{s}\right)$. The results of this automatic detection were checked by inspecting each trial individually, and were adjusted manually when necessary. The present study describes the effect of unilateral cFN inactivation on the interceptive saccades made in response to the target when it moved along the vertical meridian. The effects of fastigial inactivation on movements toward the horizontally moving target were thoroughly described elsewhere (Bourrelly et al. 2018a, b). The interceptive saccade corresponds to the first saccade made from a static target toward the target after the onset of its motion. To make sure that the interceptive saccade was not triggered prematurely, those with latency $<80 \mathrm{~ms}$ were excluded from analysis $(0.3 \%$ of the total number of trials). The Statistica software (Statsoft) was used for statistical analyses and figure illustrations. Statistical significance threshold was set to P-value $<0.05$. Because the size of deficits could differ between different injections, the mean values of the pre- and post-injection movements were compared with the non-parametric Wilcoxon test (for paired comparison). Thus, our main conclusions are based on the systematic effects that were revealed by this overall comparison across different experiments. The correlations between different behavioral measurements were evaluated with the (parametric) Bravais-Pearson test whereas the correlation between a behavioral parameters and the target speed was evaluated with the non-parametric Spearman test. 
Figure 1 illustrates with a few selected trials how a unilateral injection of muscimol in the cFN affects the eye movements made in response to a centrifugal target moving at a constant speed $(20 \%)$ along the vertical meridian. The time course of the horizontal (top row) and vertical (bottom row) components is shown for movements produced before (gray) and after muscimol injection (black) in the left (A and B: experiments $\mathrm{A} 2$ and $\mathrm{A} 3$ in monkey $\mathrm{A}$ ) or right $\mathrm{cFN}(\mathrm{C}$ : experiment Bi9 in monkey Bi). As described elsewhere (Guerrasio et al. 2010), inactivation of cFN caused a fixation offset toward the injected side. Most starting eye positions were shifted to the right after muscimol injection in the right $\mathrm{cFN}$ (see black arrow in $\mathrm{C}$ ) and to the left after muscimol injection in the left $\mathrm{cFN}$ (black arrow in A). The ipsilesional offset was not observed on every trial. We show examples (recorded during the experiments A2 and A3) in which the saccades were initiated from positions near the vertical meridian (horizontal position values close to zero in the upper graphs) but below the horizontal meridian (negative values of vertical position in the lower graphs). In addition to altering gaze direction during fixation, unilateral cFN inactivation also perturbed vertical saccades. Their trajectory was deviated horizontally toward the injected side, regardless of whether the target moved upward or downward. In the following paragraphs, after describing the velocity of their vertical component, we describe the ipsipulsion that alters the trajectory of vertical saccades.

Figure 2 approximately here

As for horizontal saccades (see Fig. 2 in Bourrelly et al. 2018a), muscimol injection in the cFN barely affected the vertical velocity of saccades. Figure 2 illustrates the vertical amplitude-peak velocity relationship for four different experiments (two per monkey; A and B: 
values are plotted for all upward and downward saccades (positive and negative amplitude values, respectively) made in response to the different target speeds. When we consider saccades of comparable vertical amplitude, we can see that the peak velocity is similar between the pre and post-injection movements.

\section{Figure 3 approximately here}

Figure 3 describes the landing position and time of interceptive saccades made toward a target moving with a constant speed $(20 \%$ s) along the vertical meridian (black: upward motion, gray: downward). For three different experiments (A3 and Bi7: left cFN inactivation; Bi9: right $\mathrm{cFN}$ inactivation), the vertical (top row) and horizontal (bottom row) landing positions are plotted as a function of their times relative to target motion onset. During the control sessions (open squares), the vertical landing position increased as the landing time increased, and the saccades were directed toward locations close to the physical target (represented by the dashed lines). After muscimol injection (filled squares), the vertical landing positions still increased as the landing time increased, regardless of the motion direction. The overlap between pre- and post-injection data points indicates that unilateral $\mathrm{cFN}$ inactivation did not noticeably affect the vertical component of interceptive saccades. Similar findings were found with respect to saccades toward a static target (Goffart et al. 2004). By contrast, the horizontal landing positions changed after muscimol injection. While they were scattered along the vertical meridian (position values close to zero) during the control sessions, their distribution was shifted toward the injected side after muscimol injection (to the left in experiments $\mathrm{A} 3$ and $\mathrm{Bi} 7$, to the right in experiment $\mathrm{Bi9}$ ). This effect is rather small in experiment A3 (B: mean \pm standard deviation values changing from $-0.1 \pm 0.3^{\circ}$ to $-0.5 \pm 0.4^{\circ}$ after muscimol injection), but the change of horizontal position was much larger in experiments Bi7 (D: from $0.0 \pm 0.3^{\circ}$ to $-3.5 \pm 1.6^{\circ}$ ), with $\mathrm{Bi} 9$ displaying intermediate values (F: from $0.3 \pm$ $0.4^{\circ}$ to $2.0 \pm 0.7^{\circ}$ ). Regardless of whether the target moved upward (black symbols) or 
downward (gray symbols), the horizontal landing position was always shifted toward the injected side. The size of the ipsipulsion was, in some cases, relatively constant (as in B) or increased with the landing time (as in D). It is worth noting that the hypermetria of ipsilesional horizontal saccades was relatively small during experiment A3 whereas it was larger during experiments Bi7 and Bi9 (see Figures 7 and 10 in Bourrelly et al. 2018a). In summary, an ipsilesional deviation was observed in the trajectory of vertical saccades during cFN inactivation. The magnitude of the ipsipulsion varied between experiments, but as we will show, it is correlated to the magnitude of the dysmetria that impairs the horizontal saccades.

To quantify the accuracy of vertical saccades, we calculated for each component the ratio of landing position to landing time. This parameter (called position/time landing) characterizes both spatial and temporal aspects of saccades made toward a moving target (Bourrelly et al. 2018a). When we consider saccades toward a target moving along the vertical meridian, the values of vertical position/time landing are expected to be close to the target speed if gaze lands next to the target location. A ratio larger than the target speed indicates an overshoot (too large amplitude) whereas a smaller value means an undershoot (too small amplitude). Concerning the horizontal component, if gaze lands close to the target, its value is expected to be close to zero because the target does not move horizontally. We will use the convention that a positive horizontal ratio indicates an ipsilesional deviation whereas a negative value is the signature of a contralesional deviation.

\section{Figure 4 approximately here}

Figure 4 shows the average vertical position/time landing relationships for each monkey and each experiment in which the target moved at constant speed. During the control sessions, the values were close to the target speed $(11.2 \pm 1.3,21.9 \pm 2.0$ and $38.9 \pm 4.6 \%$ s for the 10,20 and $40 \%$ targets, respectively). After muscimol injection, these ratios were larger $(12.3 \pm$ 
$3.8^{\circ} \mathrm{s}, 24.3 \pm 4.0^{\circ} / \mathrm{s}$ and $44.2 \pm 6.3 \%$ s for the 10,20 and $40 \%$ s targets, respectively) (Fig. 4A). This increase was small but statistically significant (Wilcoxon test, all $\mathrm{P}$ values $<0.05$ ). A stronger affect was observed in the horizontal component of vertical saccades. Figure 4B shows the average horizontal position/time landings for each tested constant speed, in each experiment and both monkeys. After muscimol injection, the horizontal position/time landings increased from $0.0 \pm 0.7 \%$ s (range: $-1.1-1.6 \%$ s) to $5.4 \pm 3.6 \%$ s (range: $0.8-12.1 \%$ s) when the target speed was $10 \%$, from $0.0 \pm 1.1 \%$ (range: $-2.6-2.9 \%$ s) to $8.0 \pm 4.9 \%$ (range: $1.8-18.6 \%$ s) with the $20 \%$ s target and from $-0.2 \pm 1.6 \%$ (range: $-2.5-2.9 \%$ s) to $12.0 \pm 7.6 \%$ (range: $3.1-$ $24.2^{\circ} / \mathrm{s}$ ) with the $40^{\circ} \%$ s target. The ranges of mean values and the examination of data points in Fig 4B indicate more variability after muscimol injection than before (see the scattering toward more positive values; note also the different scales for the $\mathrm{x}$ and $\mathrm{y}$ axes). During the control sessions, the average horizontal position/time landings were close to zero (grand averages $=$ $0.0,0.0$ and $-0.2 \%$ s for the 10,20 and $40^{\circ} / \mathrm{s}$ target, respectively; all monkeys considered). After muscimol injection, the values were larger and also increased with target speed $(5.4,8.0$ and $12.0 \%$ for the 10,20 and $40 \%$ s target, respectively). Figure $4 \mathrm{C}$ compares the average horizontal position/time landing between saccades toward the $20 \%$ s target and saccades to the $10 \%$ (gray symbols) and $40 \%$ s (black symbols) targets. The values with the $10 \%$ s target were smaller than the values with the $20 \%$ s target (gray symbols are situated below the diagonal line of equality) whereas the values with the $40 \%$ s target were larger than those obtained with the $20 \%$ s target (almost all black symbols above the diagonal line). Thus, within the same experiment, the size of the ipsipulsion was larger during saccades to the fastest target than during saccades to the slowest ones. Moreover, the injections which led to the larger horizontal errors with the $20 \%$ target were those caused the bigger changes with the other speeds. Statistically significant correlations were indeed found between the average horizontal position/time landing values calculated with the $20 \%$ and $10 \%$ targets (Bravais-Pearson correlation coefficient $\mathrm{R}=0.94, \mathrm{P}$ 
$<0.05)$ as well as between the mean values obtained with the $20 \% \mathrm{~s}$ and $40 \%$ s targets $(\mathrm{R}(\mathrm{x}, \mathrm{y})=$ $0.93, \mathrm{P}<0.05)$

\section{Figure 5 approximately here}

In our previous report, we documented the dysmetria of horizontal interceptive saccades after $\mathrm{cFN}$ inactivation: ipsilesional saccades are hypermetric whereas contralesional saccades are hypometric (Bourrelly et al. 2018a). Like the dysmetria that affects horizontal saccades toward a static target (Goffart et al. 2004, in preparation), the sizes of the ipsilesional and contralesional dysmetria are unrelated. However, it is known that the cFN projects to the region in the contralateral medullary reticular formation (medRF) where premotor inhibitory burst neurons (IBNs) are located (Noda et al. 1990) and that these neurons, in addition to firing a burst during horizontal saccades, also fire during vertical saccades (Scudder et al. 1988; van Gisbergen et al. 1981). Because of this involvement of IBNs in horizontal and vertical saccades, it is quite reasonable to consider that a common dysfunction causes the ipsipulsion of vertical saccades and the dysmetria of horizontal saccades (Goffart et al. 2004). Therefore, we tested the relation between these two disorders and found a significant correlation between the average horizontal position/time landings of ipsilesional horizontal saccades and vertical saccades toward the $10^{\circ} / \mathrm{s}(\mathrm{R}=0.77, \mathrm{P}<0.05), 20^{\circ} / \mathrm{s}(\mathrm{R}=0.62, \mathrm{P}<0.05)$ and $40 \% \mathrm{~s}(\mathrm{R}=0.81, \mathrm{P}<0.05)$ targets (Fig. 5A). When the correlation was instead tested between the horizontal position/time landings of contralesional horizontal saccades and vertical saccades, the coefficients were smaller and negative. Furthermore, the correlation did not reach statistical significance when the target moved at $10 \%(\mathrm{~s}=-0.41, \mathrm{P}>0.05)$ and $40 \% \mathrm{~s}(\mathrm{R}=-0.13, \mathrm{P}>0.05)$. A significant correlation was found only with the $20 \%$ s target $(\mathrm{R}=-0.47, \mathrm{P}<0.05)$ (Fig. 5B). Then, for each experiment, we subtracted the average contralesional position/time landing from the ipsilesional position/time landing, the resulting difference (hereafter called net bilateral effect on horizontal saccades) characterizing the dysmetria of saccades made toward a target moving 
horizontally (leftward or rightward). In this case, we found significant correlations between the horizontal position/time landings of vertical saccades and the net bilateral effect on horizontal saccades (Fig. 5C) that were stronger than those obtained with ipsilesional horizontal saccades $(10 \%$ s target: $\mathrm{R}=0.91$ versus $0.77 ; 20 \% \mathrm{R}=0.81$ versus $0.62 ; 40 \% \mathrm{~s}: \mathrm{R}=0.90$ versus 0.81$)$.

In summary, after muscimol injection in the $\mathrm{cFN}$, all vertical saccades made toward a target moving at a constant speed along the vertical meridian were deviated horizontally toward the injected side. Their vertical components were slightly affected but not as dramatically as the horizontal component. The size of the ipsipulsion differed between experiments and the average horizontal position/time landing increased with the target speed. Moreover, the ipsipulsion is correlated with the dysmetria that impaired the horizontal (ipsilesional and contralesional) saccades.

\section{Figure 6 approximately here}

In the figure $4 \mathrm{C}$, we showed that the ipsipulsion of vertical saccades depends upon the target speed. To further explore this dependence, we tested saccades toward a target that moved with continuous acceleration or deceleration. If the ipsipulsion depends on target speed, the horizontal landing position should increase with later landing times when the target accelerates but decrease or stagnate when it decelerates. Figure 6 describes the horizontal landing position and time of saccades to a target moving with an increasing (top row) and decreasing speed (bottom row) for three experiments (A3: left column; Bi8: middle and Bi9: right). During the control sessions (open squares), the saccades landed on locations situated along the vertical meridian (open symbols are close to the line of zero horizontal position) whereas after muscimol injection (filled squares), they landed on locations which were shifted toward the injected side (see negative position values in experiments $\mathrm{A} 3$ and $\mathrm{Bi} 8$ and positive values in experiment $\mathrm{Bi}$ ). For these three experiments, the ipsipulsion of vertical saccades did not depend on the 
instantaneous speed of the target. Statistically significant correlations were found in only two experiments: A6 (positive correlation $\mathrm{R}=0.54$, injection in the right $\mathrm{cFN}$ ) and $\mathrm{A} 2$ (negative correlation $\mathrm{R}=-0.35$, left $\mathrm{cFN})$. For the other experiments, no correlation was found between the horizontal landing position and the landing time when the target accelerated ( $\mathrm{R}$ values ranged from -0.25 to 0.19 , P-values $>0.05)$. Concerning the saccades toward a decelerating target, no statistically significant correlation was found between the horizontal landing position and the landing time ( $\mathrm{R}$ values ranged from -0.42 to 0.34 , P-values $>0.05$ ). In summary, we found no evidence suggesting that the ipsipulsion depends on the instantaneous target speed: the horizontal landing position neither increased with later landing times when the target accelerated nor decreased when it decelerated.

\section{Figure 7 approximately here}

Fig. 7 documents the mean values of vertical (A) and horizontal (B) position/time landing of saccades toward the accelerating (gray symbols) and decelerating (black symbols) targets, before and after muscimol injection, as a summary of our results. The vertical position/time landing of saccades was changed after muscimol injection, more with the decelerating target than with the accelerating one (Fig. 7A). With the accelerating target, the pre- and post-injection mean values of vertical position/time landing were not significantly different (Wilcoxon test, $\mathrm{P}=0.47$ ) whereas with the decelerating target, the post-injection values were significantly different from pre-injection values $(16 \%$ average increase, $\mathrm{P}<0.05)$. Regarding the horizontal position/time landing (Fig. 7B), it increased from $0.1 \pm 0.7^{\circ} / \mathrm{s}$ (range: $-0.8-1.9 \%$ s) to $5.0 \pm 2.9 \%$ (range: $0.8-9.5 \%$ s) after muscimol injection with the accelerating target and from $0.0 \pm 1.8 \%$ (range: $-3.6-3.4 \%$ s) to $11.6 \pm 5.9 \%$ (range: $2.6-20.1 \%$ s) with the decelerating target. In both groups of saccades, the changes were statistically significant $(\mathrm{P}<$ 0.05). Like saccades toward a target moving with a constant speed, the mean values of horizontal landing position were also variable between the different muscimol injections (see 
range values reported above and the scatter of post-lesion data points in Fig. 7B). Finally, the injections which led to the larger horizontal position/time landings with the $20^{\circ} / \mathrm{s}$ moving target were those which led to the bigger changes with the accelerating and decelerating targets (Fig. 7C). Statistically significant correlations were indeed found between the horizontal position/time landings of saccades toward the $20 \%$ s and those directed toward the accelerating (Bravais-Pearson correlation coefficient $\mathrm{R}(\mathrm{x}, \mathrm{y})=0.86, \mathrm{P}<0.05)$ or decelerating target $(\mathrm{R}(\mathrm{x}, \mathrm{y})$ $=0.90 \mathrm{P}<0.05)$. In summary, all vertical saccades toward a target moving with a changing speed were shifted horizontally after muscimol injection in the cFN. Like saccades toward a target moving at a constant speed, the amplitude of their vertical component was slightly increased after muscimol inactivation. Their horizontal component was biased toward the injected side with a magnitude which differed between experiments. The ipsipulsion was larger for saccades aimed toward a fast target than toward a slow target. It was also smaller when the target accelerated than when it decelerated.

As for saccades to a target moving horizontally, the larger deficit with fast targets can result from the fact that at identical landing times, a fast target is more eccentric than a slow one. The dependency of the ipsipulsion upon the target speed can result from the fact that a larger amplitude was required to intercept the target when it moves fast. Studies of vertical saccades toward a static target do indeed show that after cFN inactivation, the ipsipulsion increases with more eccentric targets (Goffart et al. 2004; Iwamoto and Yoshida 2002; Quinet and Goffart 2007). However, increasing target eccentricity enhances both the amplitude and duration of saccades for larger saccades that last longer. It is not known which of these parameters affect more the magnitude of ipsipulsion. Therefore, we tested the correlation between the horizontal landing position and saccade duration for each post-injection session. The parameters of the equations fitting the relation between the horizontal landing position and the saccade duration after muscimol injection are documented for all the experiments (upward 
and downward movements pooled together) in table 1 (constant speeds) and table 2 (changing speeds). The correlation was statistically significant in 13 out of 44 test sessions (corresponding to $30 \%$ of cases) with coefficients of correlation ranging from 0.37 to 0.72 . When we instead considered the relation between the horizontal landing position and vertical saccade amplitude, statistically significant correlations were found in 30 out of 44 sessions (corresponding to $68 \%$ of the post-injection sessions), with coefficients of correlation ranging from 0.38 to 0.81 . The parameters of the equations fitting the relation between the horizontal landing position and the vertical saccade amplitude after muscimol injection are documented for all the experiments (upward and downward movements pooled together) in table 1 (target moving at a constant speed) and table 2 (accelerating and decelerating targets). In several instances, the correlation between the saccade duration and the horizontal landing position ( $\mathrm{R}(\mathrm{Dur}, \mathrm{HorP})$ ) did not reach statistical significance whereas the correlation between the saccade amplitude and the horizontal landing position (R(Amp,HorP)) was statistically significant (see Table 1: experiments A3, A5, A6 and Bi9 for the $10^{\circ}$ s target; A2, A3, A6, Bi9 and Bi10 for the $20 \%$ target; in $\mathrm{A} 3, \mathrm{~A} 5$ and $\mathrm{Bi} 7$ for the $40 \%$ s target). Likewise, when we consider the saccades toward an accelerating target (leftmost columns in Table 2), R(Dur,HorP) was not statistically significant although $\mathrm{R}(\mathrm{Amp}, \mathrm{HorP})$ was during the experiments $\mathrm{A} 2$ and A6. Finally, when the target was decelerating (rightmost columns in Table 2), R(Dur,HorP) was not statistically significant but R(Amp,HorP) was significant during the experiments A3, A6, Bi8 and Bi10. Considering all 44 sessions, a significant correlation $\mathrm{R}($ Dur,HorP) without significant correlation $\mathrm{R}(\mathrm{Amp}, \mathrm{HorP})$ was observed in one single experiment (Bi8, accelerating target). Altogether, these results strongly suggest that the ipsipulsion increased mostly because saccades had larger amplitudes than because they lasted longer. 
To illustrate this correlation between the vertical amplitude of saccades and the ipsipulsion, Fig. 8 plots the horizontal landing position as a function of vertical saccade amplitude before and after muscimol injection. Both upward and downward saccades were included (the amplitude of downward saccades was multiplied by -1). The relations are shown for four injections made in the left cFN of monkey $\mathrm{A}$ (experiments $\mathrm{A} 2$ and $\mathrm{A} 3$, top row) and $\mathrm{Bi}$ (experiments $\mathrm{Bi} 7$ and $\mathrm{Bi} 8$, bottom) for saccades to targets moving with a constant speed (light gray, dark gray and black symbols correspond to the 10, 20 and $40 \%$ s target speeds, respectively). Negative values of horizontal eye position indicate that the saccades were deviated toward the left (inactivated side). Thus, we can see that while the target speed increases from 10 to $40 \%$ s (symbols with different shades of grey), the horizontal landing position and the vertical saccade amplitude increased. During experiment A2 (Fig. 8A), as the target speed increased, the horizontal landing position changed from $-0.3 \pm 0.3^{\circ}\left(10^{\circ} / \mathrm{s}\right)$ to $-0.7 \pm 0.5^{\circ}\left(20^{\circ} / \mathrm{s}\right)$ and $-1.4 \pm 0.8^{\circ}\left(40^{\circ} / \mathrm{s}\right)$, while the vertical amplitude increased from $2.8 \pm 0.6^{\circ}\left(10^{\circ} / \mathrm{s}\right)$ to $5.1 \pm$ $1.1^{\circ}\left(20^{\circ} / \mathrm{s}\right)$ and $10.2 \pm 1.9^{\circ}\left(40^{\circ} / \mathrm{s}\right)$. Likewise, during experiment A3 (Fig. 8B), the horizontal landing position increased from $-0.3 \pm 0.3^{\circ}$ to $-0.5 \pm 0.4^{\circ}$ and $-1.3 \pm 0.6^{\circ}$ while the vertical amplitude increased from $2.7 \pm 0.6^{\circ}$ to $5.1 \pm 1.1^{\circ}$ and $10.5 \pm 1.1^{\circ}$ (values for the 10,20 and $40 \%$ target speed, respectively). The same relationship was found in monkey Bi. During experiment Bi7 (Fig. 8C), the horizontal landing position increased from $-2.4 \pm 0.7^{\circ}$ to $-3.4 \pm$ $1.6^{\circ}$ and $-4.3 \pm 1.1^{\circ}$ and the vertical amplitude from $2.2 \pm 0.7^{\circ}$ to $5.1 \pm 1.2^{\circ}$ and $9.0 \pm 1.3^{\circ}$. Finally, during experiment Bi8 (Fig. 8D), the horizontal landing position increased from $-2.0 \pm$ $0.7^{\circ}\left(10^{\circ} / \mathrm{s}\right)$ to $-2.8 \pm 0.8^{\circ}\left(20^{\circ} / \mathrm{s}\right)$ to $-3.7 \pm 1.0^{\circ}\left(40^{\circ} / \mathrm{s}\right)$, while the vertical amplitude increased from $2.2 \pm 0.6^{\circ}$ to $5.0 \pm 1.6^{\circ}$ and $9.1 \pm 1.1^{\circ}$. A relation was observed between the horizontal landing position and the vertical amplitude of saccades. Each inset graph plotted in the right part of the panels of Figure 8 shows an overlap of data points corresponding to saccades to a target moving at constant speed (gray symbols) and to an accelerating or decelerating target 
458 (black symbols). In summary, after $\mathrm{cFN}$ inactivation, the landing position of vertical saccades

459 was deviated toward the injected side by an amount that varied between experiments and that 460 was larger when the target moved quickly than when it moved slowly. The dependency of the 461 ipsipulsion upon the target speed indicates that the saccade oculomotor system has access to 462 different signals when the target moves at different speeds. However, the use of accelerating 463 and decelerating target enabled us to exclude a dependency upon the instantaneous speed of the 464 target. Further analyses revealed that the ipsipulsion was more frequently correlated with the 465 vertical amplitude of saccades rather than with their duration. 


\section{Discussion}

This study is the first to describe the consequences of unilateral pharmacological inactivation of $\mathrm{cFN}$ on the generation of vertical saccades toward a moving target. As for the saccades toward a static target, interceptive saccades exhibit a horizontal deviation of their trajectory toward the lesioned side (ipsipulsion; Figs. 3, 4B and 7B) whereas the vertical component is barely affected (Figs. 2, 3, 4A and 7A). The magnitude of the ipsipulsion is larger for fast targets than for slowly moving targets (Fig. 4C) but the use of accelerating and decelerating targets indicates that this relation is due less to the instantaneous target speed (Fig. 6) than to the saccade size. Indeed, like saccades toward a static target, the ipsipulsion increased with the vertical amplitude of saccades (Fig. 8). Statistical analyses made across all sessions indicate that the correlations between the ipsipulsion and the vertical amplitude were more frequent than the correlations between the ipsipulsion and the duration. Moreover, in several sessions, the correlation between the ipsipulsion and the duration of saccades did not reach statistical significance whereas the correlation with the vertical amplitude was significant (Tables 1 and 2). Below, we explain the neurophysiological mechanisms leading to the ipsipulsion of vertical saccades and further develop facts which call for an alternative approach to investigate the neurophysiology of visually-guided eye movements and their cerebellar control.

\section{Figure 9 approximately here}

\section{How does bilateral fastigial activity influence the trajectory of saccades?}

Numerous works show that the activity of cFN neurons plays a crucial role in the cerebellar control of saccade generation. Two major reasons led us to investigate their influence on the trajectory of saccades toward a target moving along the vertical meridian: 1) vertical saccades are deviated horizontally after unilateral cFN inactivation and 2) the same etiology can account for this ipsipulsion and the dysmetria of horizontal saccades. In the framework of 
negative feedback control in which an internal estimate of current eye position (or displacement) is compared to a desired eye position (or displacement) command (Robinson 1975; Sparks 1989; Becker 1995; Pola 2002), a horizontal bias could impair vertical saccades in a cumulative manner as long as motor error is not zeroed and omnipause neurons do not resume their activity. Our results do not support this link between the horizontal targeting error and the duration of vertical saccades because the magnitude of the ipsipulsion was less frequently dependent upon the duration than the amplitude, and because in many cases, the correlation between the ipsipulsion and the duration did not reach statistical significance whereas the correlation between the ipsipulsion and the amplitude was statistically significant. An independence between the dysmetria and duration of gaze shifts was already noticed in the head unrestrained cat after cFN inactivation (see Figs. 5 and 6 in Goffart et al. 1998). Finally, it is worth reminding that neither Kaneko (1996) nor Soetedjo et al. (2000) reported changes in the accuracy of saccades when the nucleus raphe interpositus is lesioned or inactivated. The dysmetria of saccades after cFN inactivation is therefore not caused (but permitted) by the pause of OPNs (under the influence of the vertical burst generator). We propose that the ipsipulsion is driven by action potentials that abducens neurons emit under the influence of unbalanced input from excitatory and inhibitory burst neurons.

The known physiology of the saccade-related circuitry indeed explains the ipsipulsion of vertical saccades: if the activity of neurons in the left and right abducens nuclei is not balanced during vertical saccades, there will be horizontal deviation of the eyes. The elevated speed and the large magnitude of the ipsipulsion during head-unrestrained gaze shifts (Quinet and Goffart 2007) indicate that this imbalance is not caused by a reduced inhibition that IBNs in the contralateral medullary reticular formation exert upon neurons in the abducens nucleus ipsilateral to the inactivated cFN (synapses a and b in Fig. 9). An excitatory drive is required and we hypothesize that it is conveyed by neurons in the opposite (unaffected) cFN (synapse 
f). Transmitted by crossed projections (Noda et al. 1990), their spikes excite premotor burst neurons in the pontomedullary reticular formation ipsilateral to the inactivated $\mathrm{cFN}$, which in turn activate motor and internuclear neurons in the ipsilateral abducens nucleus (synapses $g$ and h). This crossed excitatory influence upon premotor burst neurons is supported by the fact that fastigial electrical stimulation evokes contralateral saccades (Cogdell et al. 1977; Noda et al. 1988; Quinet and Goffart 2015). It is also consistent with the contrapulsion of vertical saccades when the oculomotor vermis is asymmetrically lesioned (Takagi et al. 1998) or inactivated with muscimol (Nitta et al. 2007). This crossed fastigioreticular projection does not concern the reticulospinal neurons that Takahashi et al. (2014) identified in the cat. Indeed, if it also exists in the macaque, this fastigio-reticulospinal connection is likely involved in the postural tone of the head because the head barely moves when the cFN is electrically stimulated (Quinet and Goffart 2009). Also, during cFN inactivation in both the cat and monkey, the head exhibits an ipsilesional deviation (Goffart and Pélisson 1998; Quinet and Goffart 2005). Furthermore, the increase of ipsipulsion with saccade amplitude indicates that abducens neurons and excitatory burst neurons (EBNs) fire more as the vertical amplitude increases. Although EBNs do not normally fire during vertical saccades (Strassman et al. 1986a; Sparks et al. 2002) and unilateral inactivation of their territory yields no ipsipulsion (Barton et al. 2003), it is possible that after cFN inactivation, ipsilateral MNs, INs and EBNs abnormally fire during vertical saccades because they are released from the inhibition exerted by burst neurons (IBNs) in the contralateral reticular formation (synapses a, b and d; Cullen and Guitton 1997; Scudder et al. 1988; Strassman et al. 1986b). Those IBNs are silenced because of the suppression of their fastigial drive (synapse i) by the muscimol injection, because also of the inhibition exerted by IBNs located in the opposite side (synapse $\mathrm{j}$ ) and recruited by neurons in the unaffected cFN (synapse e). Scudder et al. (1988) indeed showed that IBNs fire more spikes as the size of vertical saccades increases (see also van Gisbergen et al. 1981). Thus, released from the 
inhibitory influence of contralateral IBNs (synapses a and b), MNs and INs emit spikes that deviate vertical saccades with a magnitude that increases with saccade size. The burst would be triggered by excitatory input from EBNs or from other neurons innervating the abducens nucleus (Langer et al. 1986; Ugolini et al. 2006).

According to the bilateral hypothesis, the activity of saccade-related fastigial neurons influences the horizontal component of all saccades (vertical and/or horizontal). Ipsilesional saccades overshoot horizontally their target because following $\mathrm{cFN}$ inactivation, the agonist motor neurons receive a drive from excitatory burst neurons (synapses $g$ and $\mathrm{h}$ in Fig. 9) that exceeds the pre-lesional drive, as it is no longer attenuated by spikes emitted by IBNs in the contralateral side (synapses a, b and d). Indeed, these IBNs not only lack their fastigial excitatory input (synapse i) but they are also inhibited by IBNs driven by neurons in the unaffected cFN (synapse e). Likewise, contralesional saccades prematurely stop for two reasons: because the agonist motor neurons lack the drive they usually receive from EBNs (as a result of suppressing their fastigial input; synapse k) and because the opposite (unaffected) cFN excites IBNs which in turn inhibit the agonist motor neurons (synapses 1 and $\mathrm{m}$ ). Thus, regardless of saccade direction, the same bilateral mechanism (i.e., an altered balance of excitatory and inhibitory input to the motor neurons) explains the effects on the horizontal component of all saccades. This conclusion is further supported when the results from the present study are synthesized with those reported in Bourrelly et al. (2018a). Indeed, the net bilateral effect of inactivation on horizontal saccades (calculated by subtracting the average contralesional position/time landing ratio from the ipsilesional ratio) is strongly correlated with the horizontal position/time landing of vertical saccades.

\section{Recasting the neurophysiology of saccades}


In the preceding section as well as in our previous reports (Bourrelly et al. 2018a,b;

Goffart et al. 2004; Guerrasio et al. 2010; Quinet \& Goffart 2007), the oculomotor disorders observed after cFN inactivation were explained without assuming perturbations of some internal (and putative) estimate of the eye kinematics, as one might expect for example, if their input from Purkinje cells in the oculomotor vermis were to encode the instantaneous velocity of saccades (Herzfeld et al. 2015). In this section, we want to further develop additional concerns which support our alternative viewpoint and call for recasting the neurophysiology of eye movements (Goffart et al. 2018; Goffart 2019).

First of all, it is important to realize that if the recording of eye muscle tension had been used more frequently (Davis-Lopez de Carrizosa et al., 2011; Gamlin and Miller; 2012; Lennerstrand et al. 1993; Miller and Robins 1992) than the recording the orientation of the eyes during neurophysiological experiments, different processes and models might have been proposed. Then, it is also important to consider the fact that the time course of saccades is not exclusively determined by the discharge of premotor and motor neurons. It involves changes in the firing rate of neurons distributed in many brain regions such as the frontal cortex (Dias and Segraves 1999), the mesencephalon (Aizawa and Wurtz 1998; Sparks et al. 1990), the pons (Kaneko and Fuchs 2006), the medio-posterior cerebellum (Goffart et al. 2003; Kojima et al. 2010) and the reticular formation (Barton et al. 2003; Soetedjo et al. 2000). Right upstream from the extraocular muscle fibers, saccades are engendered by an abrupt increase in the firing rate of motor neurons which innervate the agonist muscles and a concomitant decrease in the discharge of neurons innervating the antagonist muscles. Due to the highly damped nature of the oculomotor plant (Robinson 1964), a braking action is not exerted upon antagonist motor neurons to stop the saccade (Robinson 1970; Schiller 1970). Thus, the agonist burst duration increases with the duration of saccades and determines their size and the saturated firing rate leads to a discharge frequency which is poorly related to saccade speed (Fuchs and Luschei 
1970; Robinson 1970; Schiller 1970; Sparks and Hu 2006). Synchronous presynaptic spikes converging upon the motor neurons could be one way to overcome the limitations of interspike intervals (Schiller 1970; Goffart et al. 2017a). For the generation of horizontal saccades, the burst causing the phasic contraction of the medial rectus (and the saccade of the contralateral eye) originates in burst-tonic (internuclear) neurons in the abducens nucleus while the burst causing the phasic contraction of the lateral rectus (saccade of the ipsilateral eye) originates in abducens motoneurons. These bursts are caused by excitatory burst neurons in the paramedian pontine reticular formation (Keller 1974; Luschei and Fuchs 1972; Strassman et al. 1986a).

In several synthesis articles, we can read that the discharge profile of burst neurons is a "replica of eye velocity" (Scudder et al. 2002) and that pontine and midbrain EBNs encode saccade velocity by the frequency of spikes (Sparks 2002). Their instantaneous firing rate would be closely related with instantaneous eye velocity (Leigh and Zee 2006, page 126), as supported by several recording studies in the premotor and motor neurons (e.g., Cromer and Waitzman 2007; Cullen and Guitton 1997; King and Fuchs 1979; Sylvestre and Cullen 1999). For several years, kinematic notions were used to interpret the spiking activity of neurons and to model the generation of saccades. Yet, when we examine the firing rate of premotor neurons, we discover that they do not exhibit the same time course as instantaneous eye velocity (see Figs. 2 and 3 in Hu et al. 2007, Fig. 3C in Sparks and Hu 2006 and Fig. 5 in van Gisbergen et al. 1981). In fact, the meticulous inspection reveals that the instantaneous discharge of burst neurons is almost clock-like and quasi-regular (Hu et al. 2007), radically different from the bell-shaped profile shown by studies which convolve each spike with a Gaussian kernel.

The relation between the firing rate and the instantaneous saccade velocity was recently extended to more central neurons in the superior colliculus (Smalianchuk et al. 2018) and the oculomotor vermis (Herzfeld et al. 2015). In agreement with the crucial role of these two regions in continuously driving the saccades (Goffart et al. 2003; Goossens and van Opstal 
2006), these studies proposed that the discharge of their neurons encodes the instantaneous velocity. Two major observations must, nevertheless, be considered. Firstly, a model factoring muscle tension and its first derivative fits better the instantaneous firing rate of motoneurons than a model that uses eye position, velocity and acceleration (Davis-Lopez de Carrizosa et al., 2011). The putative velocity commands must therefore be translated into force-related commands somewhere before reaching the motor neurons. Interposed between the saccaderelated bursts of Purkinje cells and the premotor burst neurons, the caudal fastigial nuclei host a population of neurons which emit spikes that have a strong impact on the time course of saccades toward their landing position. Changes in cFN activity alter not only the endpoint of saccades (Goffart et al. 2003; Noda et al. 1991) but also their trajectory (see Figs. 1 and 7 in Goffart et al. 2004; Fig. 1 in Iwamoto and Yoshida 2002). However, the absence of relation between their firing rate and saccade velocity (Fuchs et al. 1993; Helmchen et al. 1994; Ohtsuka and Noda 1991) draws into question the suggestion that the population discharge of Purkinje cells "encodes" instantaneous saccade velocity (Herzfeld et al. 2015). When correlations are found between the population firing rate and saccade velocity, caution must be taken that they do not result from idiosyncratic (all monkeys do not make the same saccade amplitude with the same speed) or unspecific factors like different levels of motivation or arousal (Fuchs et al. 1993) as shown also in the deep superior colliculus (Ikeda and Hikosaka 2007; Soetedjo et al. 2000).

\section{Conclusion}

Instead of reflecting the reduction of an internal signal encoding the horizontal distance between gaze and target positions (or displacements), we propose that the horizontal component of saccades is the outcome of a process which restores, under bilateral fastigial control, an equilibrium (symmetry) that has been broken by asymmetric descending input (from cortical 
640 eye fields and deep superior colliculus) to the horizontal saccade generators (Goffart et al. 2018;

641 Goffart 2019). In the future, more studies will have to clarify the cerebellar control of the 642 vertical component of saccades (Quinet and Goffart 2015; Robinson 2000) and its coupling 643 with the processes controlling their horizontal component (Goffart et al. 2005). 


\section{References}

646

647

648

649

650

651

652

653

654

655

656

657

658

659

660

661

662

663

664

665

666

667

668

669

670

671

672

Aizawa H, Wurtz RH. Reversible inactivation of monkey superior colliculus. I. Curvature of saccadic trajectory. J Neurophysiol 79: 2082-2096, 1998. doi: 10.1152/jn.1998.79.4.2082

Barton EJ, Nelson JS, Gandhi NJ, Sparks DL. Effects of partial lidocaine inactivation of the paramedian pontine reticular formation on saccades of macaques. J Neurophysiol 90: 372386, 2003. doi: 10.1152/jn.01041.2002

Becker W. Models of oculomotor function: An appraisal of the engineer's intrusion into oculomotor physiology. Studies Vis Inform Processing 6: 23-46, 1995.

Bourrelly C, Quinet J, Cavanagh P, Goffart L. Learning the trajectory of a moving visual target and evolution of its tracking in the monkey. J Neurophysiol 116: 2739-2751, 2016. doi: $\underline{10.1152 / \mathrm{jn} .00519 .2016}$

Bourrelly C, Quinet J, Goffart L. The caudal fastigial nucleus and the steering of saccades toward a moving visual target. J Neurophysiol 120: 421-438, 2018a. doi:

$\underline{10.1152 / j n .00141 .2018}$

Bourrelly C, Quinet J, Goffart L. Pursuit disorder and saccade dysmetria after caudal fastigial inactivation in the monkey. J Neurophysiol 120: 1640-1654, 2018b. doi:

$\underline{10.1152 / j n .00278 .2018}$

Bourrelly C, Quinet J, Goffart L. Unsupervised dynamic morphing of a spatiotemporal visual event during its oculomotor tracking. J Vision 14: 492, 2014.

Buzunov E, Mueller A, Straube A, Robinson FR. When during horizontal saccades in monkey does cerebellar output affect movement? Brain Res 1503: 33-42, 2013. doi:

$\underline{10.1016 / j . b r a i n r e s .2013 .02 .001}$

Cogdell B, Hassul M, Kimm J. Fastigial evoked eye movement and brain stem neuronal behavior in the alert monkey. Arch Otolaryngol 103: 658-666, 1977. doi:

$\underline{10.1001 / \text { archotol.1977.00780280058008 }}$

Cromer JA, Waitzman DM. Comparison of saccade-associated neuronal activity in the primate central mesencephalic and paramedian pontine reticular formations. J Neurophysiol 98: 835-850, 2007. doi: 10.1152/jn.00308.2007 
673 Cullen KE, Guitton D. Analysis of primate IBN spike trains using system identification

674 techniques. I. Relationship to eye movement dynamics during head-fixed saccades. J

675 Neurophysiol 78: 3259-3282, 1997. doi : 10.1152/jn.1997.78.6.3259

676 Davis-López de Carrizosa MA, Morado-Díaz CJ, Miller JM, de la Cruz RR, Pastor ÁM. Dual 677 encoding of muscle tension and eye position by abducens motoneurons. J Neurosci 31: 2271678 2279, 2011. doi: 10.1523/JNEUROSCI.5416-10.2011

679 Dias EC, Segraves MA. Muscimol-induced inactivation of monkey frontal eye field: effects 680 on visually and memory-guided saccades. J Neurophysiol 81: 2191-2214, 1999. doi:

$681 \quad \underline{10.1152 / j n .1999 .81 .5 .2191}$

682 Fuchs AF, Brettler S, Ling L. Head-free gaze shifts provide further insights into the role of the 683 medial cerebellum in the control of primate saccadic eye movements. J Neurophysiol 103: 2158-2173, 2010. doi: 10.1152/jn.91361.2008

685 Fuchs AF, Luschei ES. Firing patterns of abducens neurons of alert monkeys in relationship 686 to horizontal eye movement. J Neurophysiol 33: 382-392, 1970. doi:

687 $\underline{10.1152 / j n .1970 .33 .3 .382}$

688 689

690

691

692

693

694

695

696

697

698

699

700

Fuchs AF, Kaneko CRS, Scudder CA. Brainstem control of saccadic eye movements. Ann Rev Neurosci 8: 307-337, 1985. doi: 10.1146/annurev.ne.08.030185.001515

Fuchs AF, Robinson FR, Straube A. Role of the caudal fastigial nucleus in saccade generation. I. Neuronal discharge pattern. J Neurophysiol 70: 1723-1740, 1993. doi: $\underline{10.1152 / j n .1993 .70 .5 .1723}$

Gamlin, PD, Miller JM. Extraocular muscle motor units characterized by spike-triggered averaging in alert monkey. J Neurosci Methods 204: 159-167, 2012. doi: 10.1016/j.jneumeth.2011.11.012

Goffart L. Kinematics and the neurophysiological study of visually-guided eye movements. Prog Brain Res 249:375-384, 2019. doi: 10.1016/bs.pbr.2019.03.027

Goffart L, Bourrelly C, Quinet J. Synchronizing the tracking eye movements with the motion of a visual target: Basic neural processes. Prog Brain Res;236: 243-268, 2017a. doi: 
Goffart L, Bourrelly C, Quinton JC. Neurophysiology of visually-guided eye movements: Critical review and alternative viewpoint. J Neurophysiol 120: 3234-3245, 2018. doi: $\underline{10.1152 / j n .00402 .2018}$

Goffart L, Chen LL, Sparks DL. Saccade dysmetria during functional perturbation of the caudal fastigial nucleus in the monkey. Ann NY Acad Sci 1004: 220-228, 2003. doi:

\section{$\underline{10.1196 / \text { annals.1303.019 }}$}

Goffart L, Chen LL, Sparks DL. Deficits in saccades and fixation during muscimol inactivation of the caudal fastigial nucleus in the rhesus monkey. J Neurophysiol 92: 33513367, 2004. doi: 10.1152/jn.01199.2003

Goffart L, Koene A, Quinet J. Coupling between horizontal and vertical saccade generators after muscimol injection in the monkey caudal fastigial nucleus. Soc Neurosc Abstr 475.2, 2005.

Goffart L, Pélisson D. Orienting gaze shifts during muscimol inactivation of caudal fastigial nucleus in the cat. I. Gaze dysmetria. J Neurophysiol 79: 1942-1958, 1998. doi:10.1152/jn.1998.79.4.1942

Goffart L, Pélisson D, Guillaume A. Orienting gaze shifts during muscimol inactivation of caudal fastigial nucleus in the cat. II. Dynamics and eye-head coupling. J Neurophysiol 79: 1959-1976, 1998. doi: 10.1152/jn.1998.79.4.1959

Goffart L, Quinet J, Bourrelly C. Cerebellar control of saccades by the size of the active population in the caudal fastigial nucleus. S-5042-SfN, $2017 \mathrm{~b}$.

Goossens HH, Van Opstal AJ. Dynamic ensemble coding of saccades in the monkey superior colliculus. J Neurophysiol 95: 2326-2341, 2006. doi: 10.1152/jn.00889.2005

Guerrasio L, Quinet J, Büttner U, Goffart L. Fastigial oculomotor region and the control of foveation during fixation. J Neurophysiol 103: 1988-2001, 2010. doi: 10.1152/jn.00771.2009

Helmchen C, Straube A, Büttner U. Saccade-related activity in the fastigial oculomotor region of the macaque monkey during spontaneous eye movements in light and darkness. Exp Brain Res 98: 474-482, 1994. doi: 10.1007/BF00233984 
Hepp K, Henn V, Vilis T, Cohen B. Brainstem regions related to saccade generation. In: The neurobiology of saccadic eye movements. RH Wurtz and ME Goldberg (eds), Elsevier, 1989, pp 105-212.

Herzfeld DJ, Kojima Y, Soetedjo T, Shadmehr R. Encoding of action by the Purkinje cells of the cerebellum. Nature 526: 439-442, 2015. doi: 10.1038/nature15693

Horn AK. The reticular formation. Progr Brain Res 151: 127-155, 2006. doi:

Hu X, Jiang H, Gu C, Li C, Sparks DL. Reliability of oculomotor command signals carried by individual neurons. Proc Nat Acad Sci 104: 8137-8142, 2007. doi: 10.1073/pnas.0702799104

Ikeda T, Hikosaka O. Positive and negative modulation of motor response in primate superior colliculus by reward expectation. J Neurophysiol 98: 3163-3170, 2007. doi:

$\underline{10.1152 / j n .00975 .2007}$

Iwamoto Y, Yoshida K. Saccadic dysmetria following inactivation of the primate fastigial oculomotor region. Neurosci Lett 325: 211-215, 2002. doi: 10.1016/s0304-3940(02)00268-9

Kaneko CR. Effect of ibotenic acid lesions of the omnipause neurons on saccadic eye movements in rhesus macaques. J Neurophysiol 75: 2229-2242, 1996. doi: 10.1152/jn.1996.75.6.2229

Kaneko CR, Fuchs AF. Effect of pharmacological inactivation of nucleus reticularis tegmenti pontis on saccadic eye movements in the monkey. $\mathrm{J}$ Neurophysiol 95: 3698-3711, 2006. doi: $\underline{10.1152 / \mathrm{jn} .01292 .2005}$

Keller EL. Participation of medial pontine reticular formation in eye movement generation in monkey. J Neurophysiol 37: 316-332, 1974. doi: 10.1152/jn.1974.37.2.316

King WM, Fuchs AF. Reticular control of vertical saccadic eye movements by mesencephalic burst neurons. J Neurophysiol 42: 861-876, 1979. doi: 10.1152/jn.1979.42.3.861

Kleine JF, Guan Y, Büttner U. Saccade-related neurons in the primate fastigial nucleus: what do they encode? J Neurophysiol 90: 3137-3154, 2003. doi: 10.1152/jn.00021.2003 
753

754

755

756

757

758

759

760

761

762

763

764

765

766

767

768

769

770

771

772

773

774

775

776

777

778

779

Kojima Y, Soetedjo R, Fuchs AF. Effects of GABA agonist and antagonist injections into the oculomotor vermis on horizontal saccades. Brain Res 1366: 93-100, 2010. doi: $\underline{10.1016 / j . b r a i n r e s .2010 .10 .027}$

Langer T, Kaneko CR, Scudder CA, Fuchs AF. Afferents to the abducens nucleus in the monkey and cat. J Comp Neurol 245: 379-400, 1986. doi : 10.1002/cne.902450307

Leigh RJ, Zee DS. The neurology of eye movements. Oxford University Press, 2006.

Lennerstrand G, Tian S, Zhao TX. Force development and velocity of human saccadic eye movements. I: Abduction and adduction. Clinical vision sciences 8: 295-305, 1993.

Luschei ES, Fuchs AF. Activity of brain stem neurons during eye movements of alert monkeys. J Neurophysiol 35: 445-461, 1972. doi: 10.1152/jn.1972.35.4.445

Miller JM, Robins D. Extraocular muscle forces in alert monkey. Vision Res 32: 1099-1113, 1992. doi: 10.1016/0042-6989(92)90010-g

Moschovakis AK, Scudder CA, Highstein SM. The microscopic anatomy and physiology of the mammalian saccadic system. Prog Neurobiol 50: 133-254, 1996. doi: 10.1016/s0301$\underline{0082(96) 00034-2}$

Nitta T, Akao T, Kurkin S, Fukushima K. Involvement of the cerebellar dorsal vermis in vergence eye movements in monkeys. Cereb Cortex 18: 1042-1057, 2008. doi: $10.1093 /$ cercor/bhm143

Noda H, Murakami S, Warabi T. Effects of fastigial stimulation upon visually-directed saccades in macaque monkeys. Neurosci Res 10(3):188-99, 1991. doi: $\underline{10.1016 / 0168-}$ $\underline{0102(91) 90056-5}$

Noda H, Murakami S, Yamada J, Tamada J, Tamaki Y, Aso T. Saccadic eye movements evoked by microstimulation of the fastigial nucleus of macaque monkeys. J Neurophysiol 60 : 1036-1052, 1988. doi: 10.1152/jn.1988.60.3.1036

Noda H, Sugita S, Ikeda Y. Afferent and efferent connections of the oculomotor region of the fastigial nucleus in the macaque monkey. J Comp Neurol 302: 330-348, 1990. doi: $\underline{10.1002 / \mathrm{cne} .903020211}$ 
780

781

782

783

784

785

786

787

788

789

790

791

792

793

794

795

796

797

798

799

800

801

802

803

804

Ohtsuka K, Noda H. Saccadic burst neurons in the oculomotor region of the fastigial nucleus of macaque monkeys. J Neurophysiol 65: 1422-1434, 1991. doi: 10.1152/jn.1991.65.6.1422

Optican LM. Sensorimotor transformation for visually guided saccades. Ann NY Acad Sci 1039: 132-148, 2005. doi: 10.1196/annals.1325.013

Pola J. Models of the saccadic and smooth pursuit systems. In Models of the visual system, G. K. Hung et al. (eds.), Springer, Boston, MA, 2002, pp. 385-429.

Quinet J, Goffart L. Saccade dysmetria in head unrestrained gaze shifts after muscimol inactivation of the caudal fastigial nucleus in the monkey. J Neurophysiol 93: 2343-2349, 2005. doi: 10.1152/jn.00705.2004

Quinet J, Goffart L. Head unrestrained gaze shifts after muscimol injection in the caudal fastigial nucleus of the monkey. J Neurophysiol 98: 3269-3283, 2007. doi: $\underline{10.1152 / j n .00741 .2007}$

Quinet J, Goffart L. Electrical microstimulation of the fastigial oculomotor region in the headunrestrained monkey. J Neurophysiol 102: 320-336, 2009. doi: 10.1152/jn.90716.2008

Quinet J, Goffart L. Does the brain extrapolate the position of a transient moving target? J Neurosci 35: 11780-11790, 2015a. doi: 10.1523/JNEUROSCI.1212-15.2015

Quinet J, Goffart L. Cerebellar control of saccade dynamics: contribution of the fastigial oculomotor region. J Neurophysiol 113: 3323-3336, 2015b. doi: 10.1152/jn.01021.2014

Quinet J, Goffart L. Bilateral fastigial control of the horizontal amplitude of saccades: evidence from studying the orthogonal component after unilateral inactivation. Soc Neurosc Abstr 55.03, 2016.

Robinson DA. The mechanics of human saccadic eye movement. J Physiol 174: 245-264, 1964. doi: 10.1113/jphysiol.1964.sp007485

Robinson DA. Oculomotor unit behavior in the monkey. J Neurophysiol 33: 393-403,1970. doi: $\underline{10.1152 / j n .1970 .33 .3 .393}$ 
805

806

807

808

809

810

811

812

813

814

815

816

817

818

819

820

821

822

823

824

825

826

827

828

829

830

831

Robinson DA. A quantitative analysis of extraocular muscle cooperation and squint. Investigative Ophthalmology \& Visual Sci. 14: 801-825, 1975.

Robinson FR. Role of the cerebellar posterior interpositus nucleus in saccades I. Effect of temporary lesions. J Neurophysiol 84: 1289-1302, 2000. doi: 10.1152/jn.2000.84.3.1289

Robinson FR, Fuchs AF. The role of the cerebellum in voluntary eye movements. Annu Rev Neurosci 24: 981-1004, 2001. doi: 10.1146/annurev.neuro.24.1.981

Robinson FR, Straube A, Fuchs AF. Role of the caudal fastigial nucleus in saccade generation. II. Effects of muscimol inactivation. J Neurophysiol 70: 1741-1758, 1993. doi: $\underline{10.1152 / j n .1993 .70 .5 .1741}$

Schiller PH. The discharge characteristics of single units in the oculomotor and abducens nuclei of the unanesthetized monkey. Exp Brain Res 10: 347-362, 1970. doi: $\underline{10.1007 / \mathrm{BF} 02324764}$

Scudder CA, Fuchs AF, Langer TP. Characteristics and functional identification of saccadic inhibitory burst neurons. J Neurophysiol 59: 1430-1454, 1988. doi:

$\underline{10.1152 / j n .1988 .59 .5 .1430}$

Scudder CA, Kaneko CS, Fuchs AF. The brainstem burst generator for saccadic eye movements: a modern synthesis. Exp Brain Res 142: 439-462, 2002. doi: 10.1007/s00221$\underline{001-0912-9}$

Smalianchuk I, Jagadisan UK, Gandhi NJ. Instantaneous midbrain control of saccade velocity. J. Neurosci. 38: 10156-10167, 2018. doi: 10.1523/JNEUROSCI.0962-18.2018

Soetedjo R, Kaneko CR, Fuchs AF. Evidence that the superior colliculus participates in the feedback control of saccadic eye movements. J Neurophysiol 87: 679-695, 2000. doi: $\underline{10.1152 / \mathrm{jn} .00886 .2000}$

Sparks DL. The neural encoding of the location of targets for saccadic eye movements. J Exp Biol 146: 195-207, 1989. doi:

Sparks DL. The brainstem control of saccadic eye movements. Nat Rev Neurosci 3: 952-964, 2002. doi: $\underline{10.1038 / \mathrm{nrn} 986}$ 
832

833

834

835

836

837

838

839

840

841

842

843

844

845

846

847

848

849

850

851

852

853

854

855

856

857

858

859

Sparks DL, Barton EJ. Neural control of saccadic eye movements. Curr Opin Neurobiol 3: 966-972, 1993. doi: 10.1016/0959-4388(93)90169-y

Sparks DL, Barton EJ, Gandhi NJ, Nelson J. Studies of the role of the paramedian pontine reticular formation in the control of head-restrained and head-unrestrained gaze shifts. Annals NY Acad Sciences 956: 85-98, 2002. doi: 10.1111/j.1749-6632.2002.tb02811.x

Sparks DL, Hu X. Saccade initiation and the reliability of motor signals involved in the generation of saccadic eye movements. In Novartis Foundation Symposium (Vol. 270, p. 75). Chichester; New York; John Wiley 1999, 2006.

Sparks DL, Lee C, Rohrer WH. Population coding of the direction, amplitude, and velocity of saccadic eye movements by neurons in the superior colliculus. Cold Spring Harb Symp Quant Biol 55: 805-811, 1990. doi: 10.1101/sqb.1990.055.01.075

Strassman A, Highstein SM, McGrea RA. Anatomy and physiology of saccadic burst neurons in the alert squirrel monkey. I. Excitatory burst neurons. J Comp Neurol 249: 337-357, 1986a. doi: $10.1002 /$ cne. 902490303

Strassman A, Highstein SM, McCrea RA. Anatomy and physiology of saccadic burst neurons in the alert squirrel monkey. II. Inhibitory burst neurons. J Comp Neurol 249: 358-380, 1986b. doi: $10.1002 /$ cne.902490304

Sylvestre PA and Cullen KE. Quantitative analysis of abducens neuron discharge dynamics during saccadic and slow eye movements. J Neurophysiol 82: 2612-2632, 1999. doi: $\underline{10.1152 / j n .1999 .82 .5 .2612}$

Takagi M, Zee DS, Tamargo RJ. Effects of lesions of the oculomotor vermis on eye movements in primate: saccades. J Neurophysiol 80: 1911-1931, 1998. doi: 10.1152/jn.1998.80.4.1911

Takahashi M, Sugiuchi Y, Shinoda Y. Convergent synaptic inputs from the caudal fastigial nucleus and the superior colliculus onto pontine and pontomedullary reticulospinal neurons. $\mathrm{J}$ Neurophysiol 111: 849-967, 2014. doi: 10.1152/jn.00634.2013

Ugolini G, Klam F, Doldan Dans M, Dubayle D, Brandi A-M, Büttner-Ennever J, Graf W. Horizontal eye movement networks in primates as revealed by retrograde transneuronal 
860 transfer of rabies virus: differences in monosynaptic input to "slow" and "fast" abducens

861 motoneurons. J Comp Neurol 20: 498: 762-785, 2006. 10.1002/cne.21092

862 van Gisbergen JAM, Robinson DA, Gielen S. A quantitative analysis of generation of

863 saccadic eye movements by burst neurons. J Neurophysiol 45: 417-442, 1981. doi:

$864 \quad \underline{10.1152 / j n .1981 .45 .3 .417}$

865 
867

868

869

870

871

872

873

874

875

876

877

878

879

880

881

882

883

884

885

886

887

888

889

890

891

892

893

894

895

Fig. 1. Effect of unilateral muscimol injection in the caudal fastigial nucleus on tracking a visual target moving along the vertical meridian. The time course of eye movements produced before (gray) and after (black) unilateral muscimol injection in the cFN is shown for six different trials. The eye position (horizontal: upper row; vertical: bottom row) is plotted as a function of time after target motion onset. The target moved at the constant speed of $20 \%$ s. The selected trials were recorded during the experiments $\mathrm{A} 2$ ( $\mathrm{A}$, injection in left $\mathrm{cFN})$ and $\mathrm{A} 3(\mathrm{~B}$, left $\mathrm{cFN}$ ) in monkey $\mathrm{A}$ and the experiment $\mathrm{Bi} 9(\mathrm{C}$, injection in the right $\mathrm{cFN})$ in monkey $\mathrm{Bi}$.

Fig. 2. Amplitude-peak velocity relationship of the vertical component of interceptive saccades toward a target moving along the vertical meridian. This relationship is shown for two experiments made in each monkey (upper row: A2 and A3 in monkey A; lower row: Bi7 and Bi8 in monkey Bi), before (gray symbols) and after muscimol injection in the left cFN (black symbols). The different symbols indicate the different target speeds $(\bullet: 10 \%$ s, $\mathbf{m}: 20 \%$ s, $*: 40 \%$, $\boldsymbol{\Delta}$ : accelerating target, $\downarrow$ : decelerating target). The number of observations are reported in the tables 1 and 2.

Fig. 3. Landing position and time of saccades toward a target moving at constant speed along the vertical meridian. The vertical (top row) and horizontal (bottom row) landing positions are plotted as a function of the time after target motion onset when the target moved vertically at $20 \%$ s. Data from before (open symbols) and after (solid symbols) muscimol injection is plotted. Black and gray symbols correspond to the upward and downward moving target, respectively. For each monkey, the effects of muscimol injection in the left or right $\mathrm{cFN}$ are documented (left cFN: experiments $\mathrm{A} 3$ and Bi7: A-D, right cFN: experiment Bi9: E-F). The dashed line corresponds to the target position.

Fig. 4. Position/time landing of saccades toward a target moving at constant speed along the vertical meridian. The average values of the vertical (panel A) and horizontal (panel B) components are plotted for the pre- and post-injection sessions of each experiment (square symbols: monkey A; circle symbols: monkey $\mathrm{Bi}$ ). The light gray, dark gray and black symbols 
correspond to the 10, 20 and $40 \%$ s target speeds, respectively. Open and filled symbols correspond to the upward and downward moving target, respectively. To illustrate the influence of target speed, the post-injection horizontal average position/time landing of saccades to the $10 \%$ and $40 \% \mathrm{~s}$ targets is plotted as a function of the average values obtained with the $20 \%$ target (panel C). Diagonal gray lines correspond to equality between abscissae and ordinate values.

Fig. 5. Comparing the effects on horizontal and vertical saccades. The post-injection average values of horizontal position/time landing of vertical saccades are plotted as a function of the ipsilesional (panel A) and contralesional (panel B) position/time landing of horizontal saccades (previously described in Bourrelly et al. 2018a) for each experiment and each monkey (square symbols: monkey A; circle symbols: monkey $\mathrm{Bi}$ ). The panel $\mathrm{C}$ shows the horizontal position/time landing of vertical saccades after muscimol injection as a function of the net bilateral effect on horizontal saccades (difference of ipsilesional and contralesional horizontal position/ time landing ratios). The light gray, dark gray and black symbols correspond to the 10,20 and $40 \%$ s target speeds, respectively. Open and filled symbols correspond to the upward and downward moving target, respectively.

Fig. 6. Landing position and time of saccades toward a target moving with a non-constant speed along the vertical meridian. The horizontal landing positions are plotted as a function of the landing times for saccades made toward an accelerating (A, B and C) or decelerating (D, E and F) target, before (open symbols) and after (filled symbols) muscimol injection. Black and gray symbols correspond to the upward and downward moving target, respectively. The dashed lines show the horizontal target position.

Fig. 7. Position/time landing of saccades toward a target moving along the vertical meridian with a non-constant speed. The average values of the vertical (panel A) and horizontal (panel B) component were calculated for the pre- and post-injection sessions of each experiment and plotted for each monkey (square symbols: monkey A; circle symbols: monkey Bi). The gray and black symbols correspond to the accelerating and decelerating target, respectively. Open and filled symbols correspond to the upward and downward moving target, respectively. To 
927 illustrate the effect of target speed, the post-injection horizontal average position/time landing

928 of saccades to the accelerating and decelerating targets is plotted as a function of the values 929 obtained with the $20 \%$ s target (constant speed) (panel C). Diagonal gray lines correspond to 930 unity lines.

932 Fig. 8. Horizontal landing position of saccades toward a target moving along the vertical 933 meridian. The horizontal landing positions are plotted as a function of the vertical amplitude 934 after muscimol injection in the left cFN in monkey $\mathrm{A}$ (A and B: experiments $\mathrm{A} 2$ and $\mathrm{A} 3$ ) and 935 monkey Bi (C and D: experiments Bi7 and Bi8). The light gray, dark gray and black symbols 936 correspond to the 10,20 and $40 \%$ s target speed, respectively. Open and filled symbols 937 correspond to the upward and downward moving target, respectively. The relation obtained 938 with saccades toward a target moving with changing speeds are shown in the insets (gray 939 symbols: constant speeds, black symbols: changing speeds).

940 Fig. 9. Pathophysiology of the ipsipulsion of vertical saccades after muscimol injection in the 941 right caudal fastigial nucleus. The arrows correspond to excitatory connections whereas the 942 connecting lines ended by a circle depict inhibitory connections. The gray stain illustrates the 943 muscimol spread. MR: medial rectus; LR: lateral rectus; MNs: motoneurons; INs: internuclear 944 neurons; EBNs and IBNs: excitatory and inhibitory burst neurons; SFNs: saccade-related 945 fastigial neurons. See text for the detailed explanation of the small letters. 


\section{Legends of tables}

948 Table 1. Relation between horizontal landing position and both vertical saccade duration and 949 amplitude after cFN inactivation (target moving at constant speed). Values are the slope, $\mathrm{y}$ 950 intercepts and coefficient of determination of the regression lines that fit the relationship 951 between the horizontal landing position and the vertical amplitude or duration of saccades 952 toward a target moving at constant speed (upward and downward movement pooled together). 953 Injections are labeled as defined in the text. The side and volume of injection are also indicated. 954 Bold numerical values correspond to statistically significant correlations $(\mathrm{P}<0.05)$.

955

956 Table 2. Relation between horizontal landing position and both vertical saccade duration and 957 amplitude after $\mathrm{cFN}$ inactivation (accelerating and decelerating target). Values are the slope, y 958 intercepts, and coefficient of determination of the regression lines that fit the relationships 959 between horizontal landing position and the vertical amplitude and duration of saccades toward 960 a target moving with an increasing speed (from 0 to $40 \%$, accelerating target) or decreasing 961 speed (from 40 to $0 \%$, decelerating target). Upward and downward movement are pooled 962 together. Injections are labeled as defined in the text. The side and volume of injection are also 963 indicated. Bold numerical values correspond to statistically significant correlations $(\mathrm{P}<0.05)$. 964 


\section{Acknowledgements:}

967 Supported by the Centre National de la Recherche Scientifique, this work received funding 968 from the European Research Council under the European Union's Seventh Framework 969 Programme (FP7/2007-2013/ERC grant agreement no. AG324070 with Patrick Cavanagh) and 970 from the Agence Nationale de la Recherche (Grant VISAFIX). This work was also made 971 possible thanks to a support from the Fondation pour la Recherche Médicale 972 (FDT20160435585) to CB, and from the Fondation de France (Berthe Fouassier 0039352) to 973 JQ. The authors thank Dr Paul May for his corrections and suggestions for clarification, Marc

974 Martin, Luc Renaud for outstanding zootechnical and surgical assistance, Xavier Degiovanni 975 and Joël Baurberg for technical assistance, Ivan Balansard for veterinarian surveillance, and Dr 976 Ivo Vanzetta for kindly lending us one monkey (Bi). 
Fig. 1

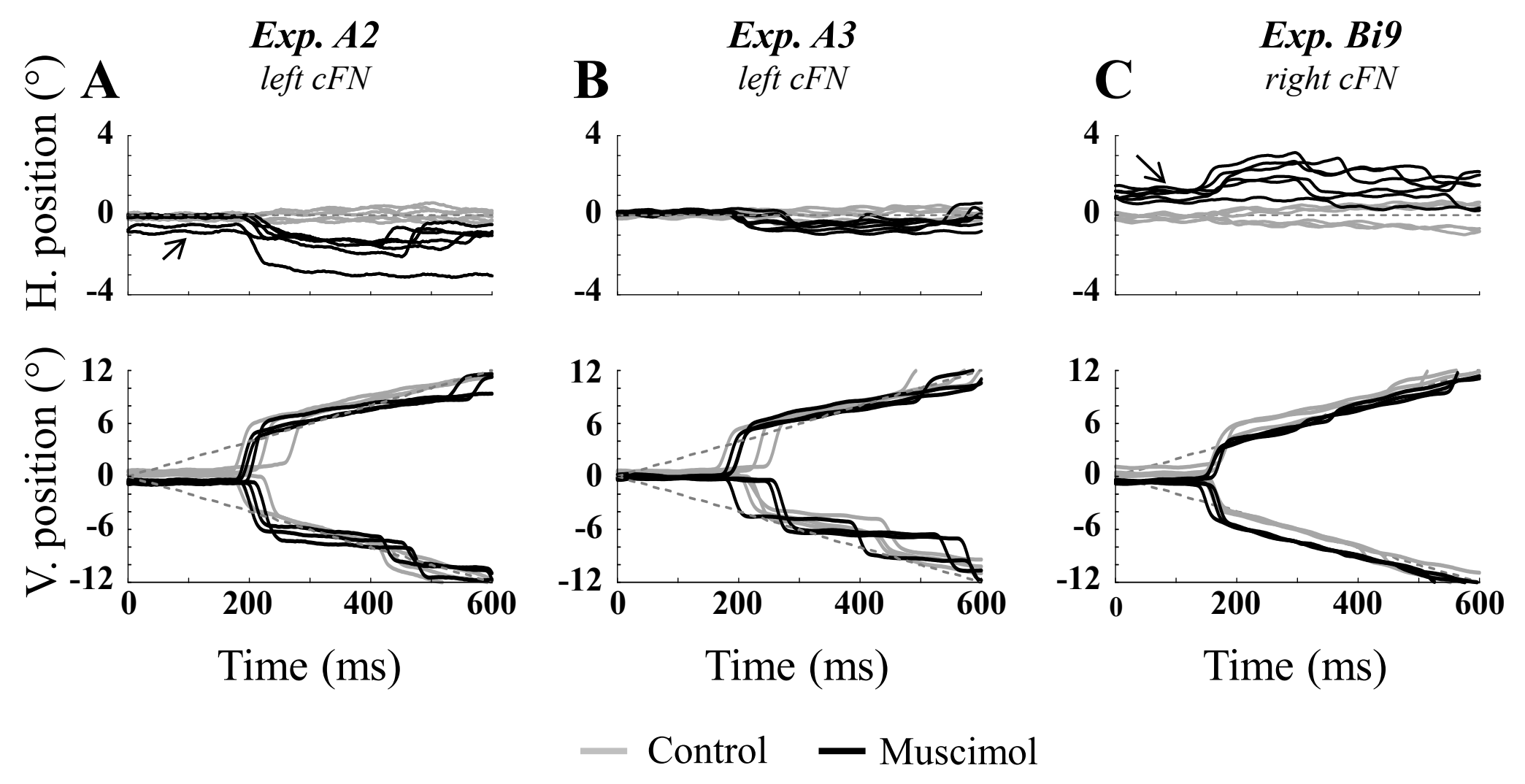


Fig. 2
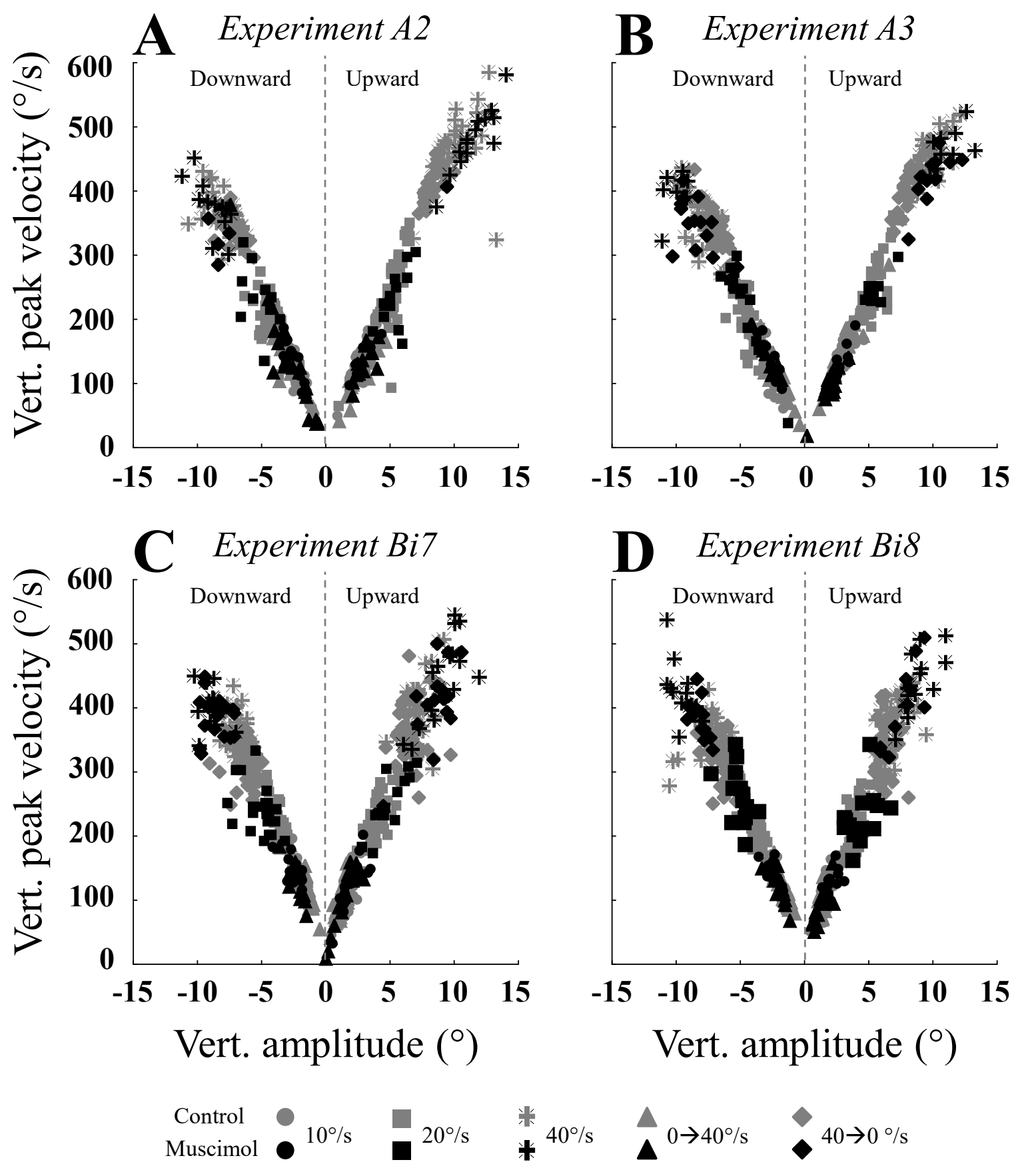
Fig. 3

\section{Constant target speed}

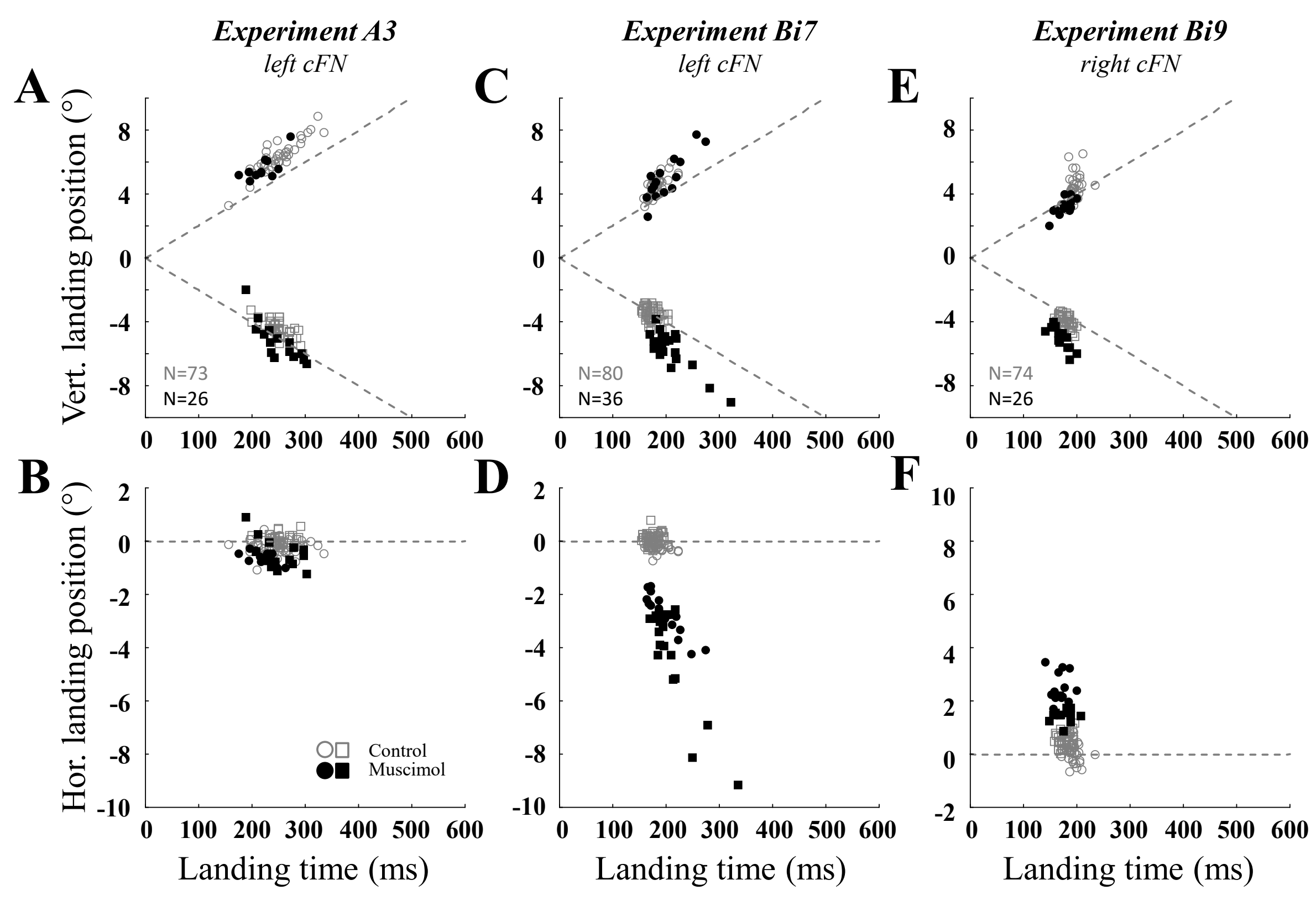


Fig. 4

\section{Constant target speed}
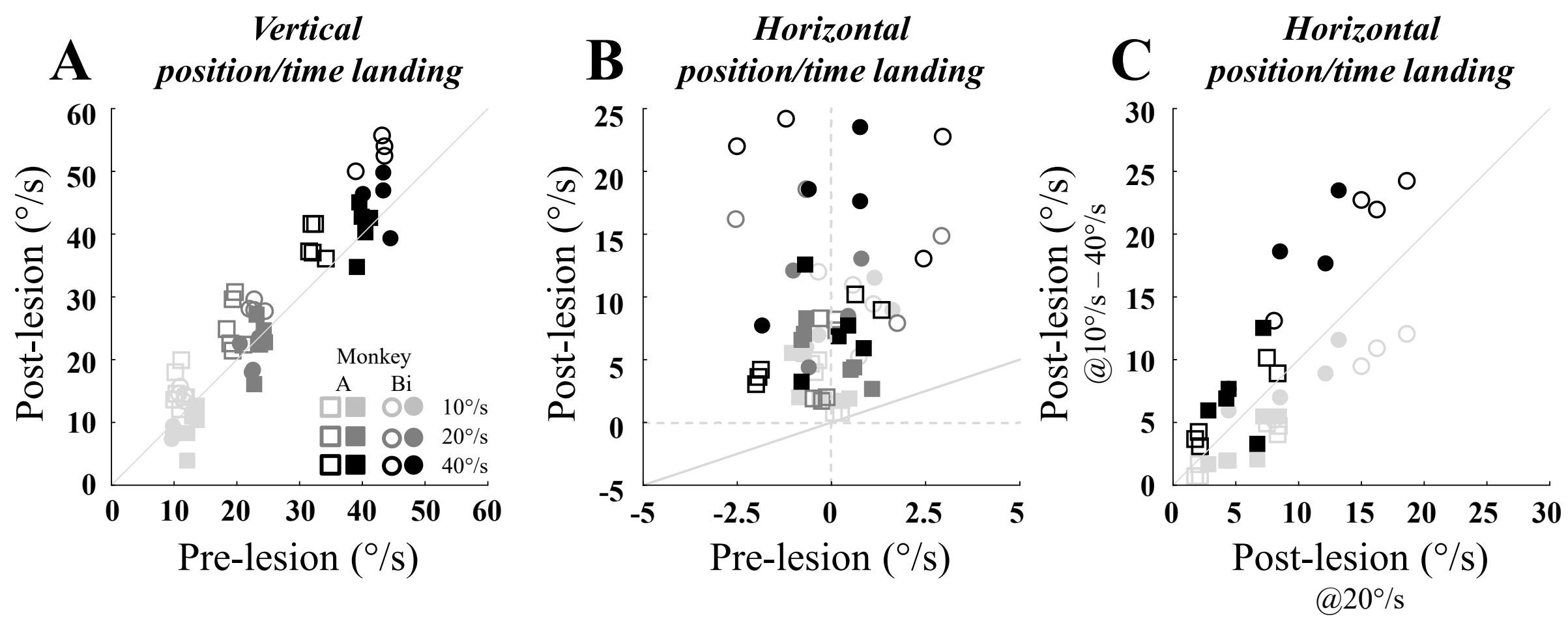
Fig. 5

\section{Constant target speed}
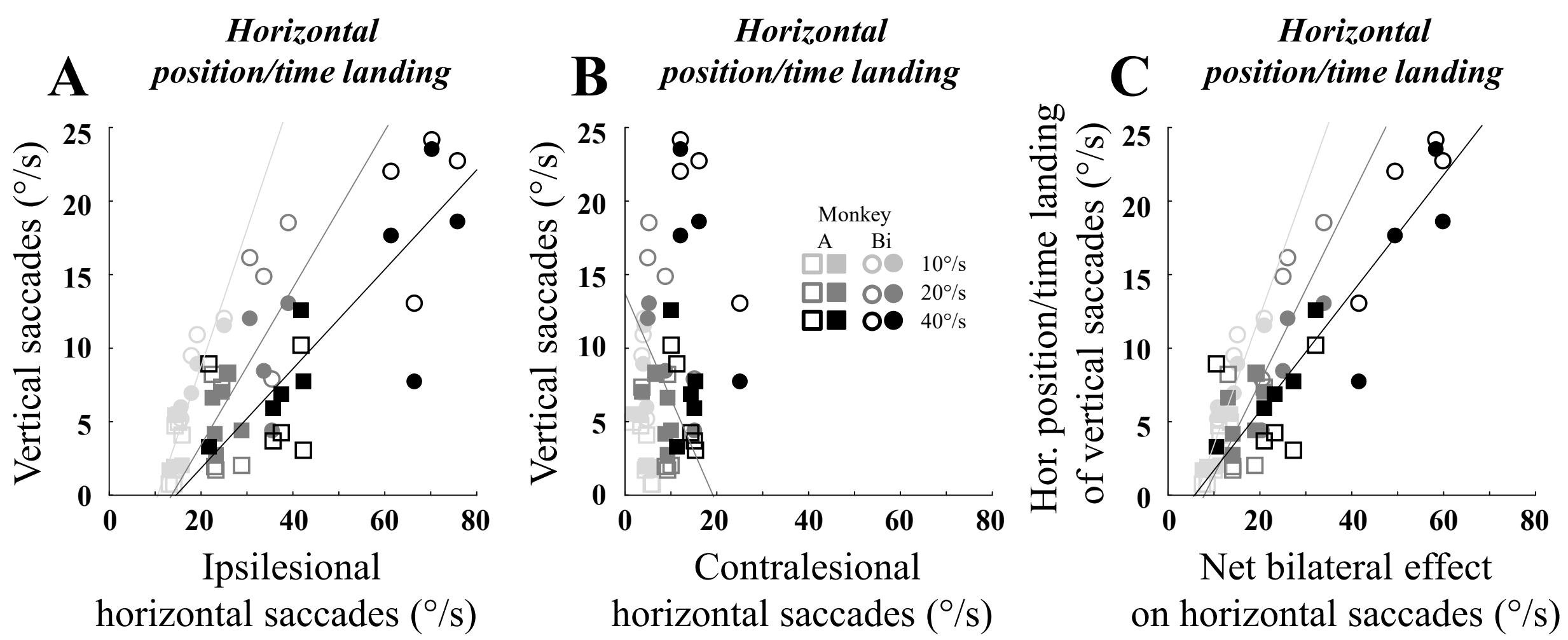


\section{Changing target speed}
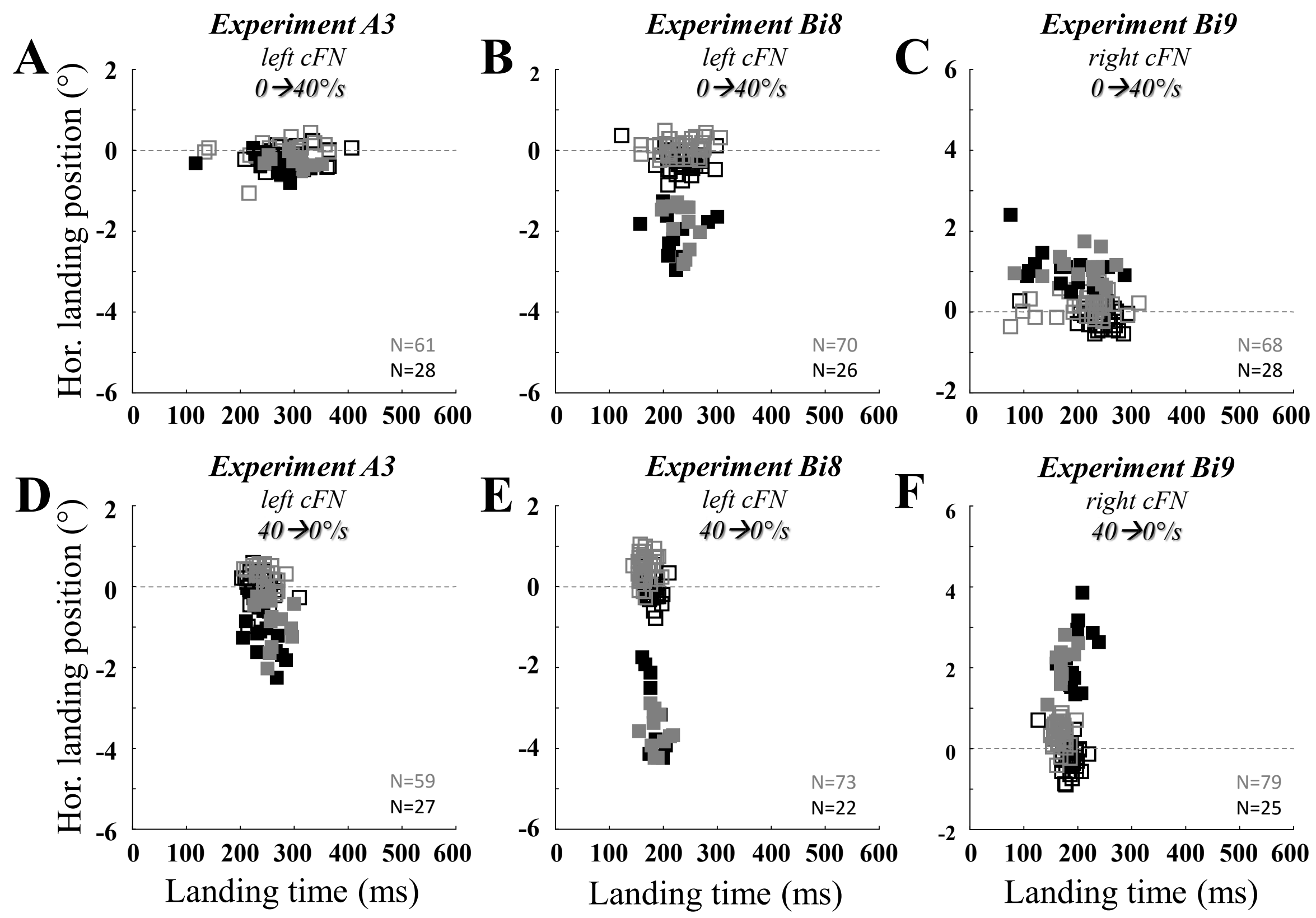
Fig. 7

\section{Changing target speed}
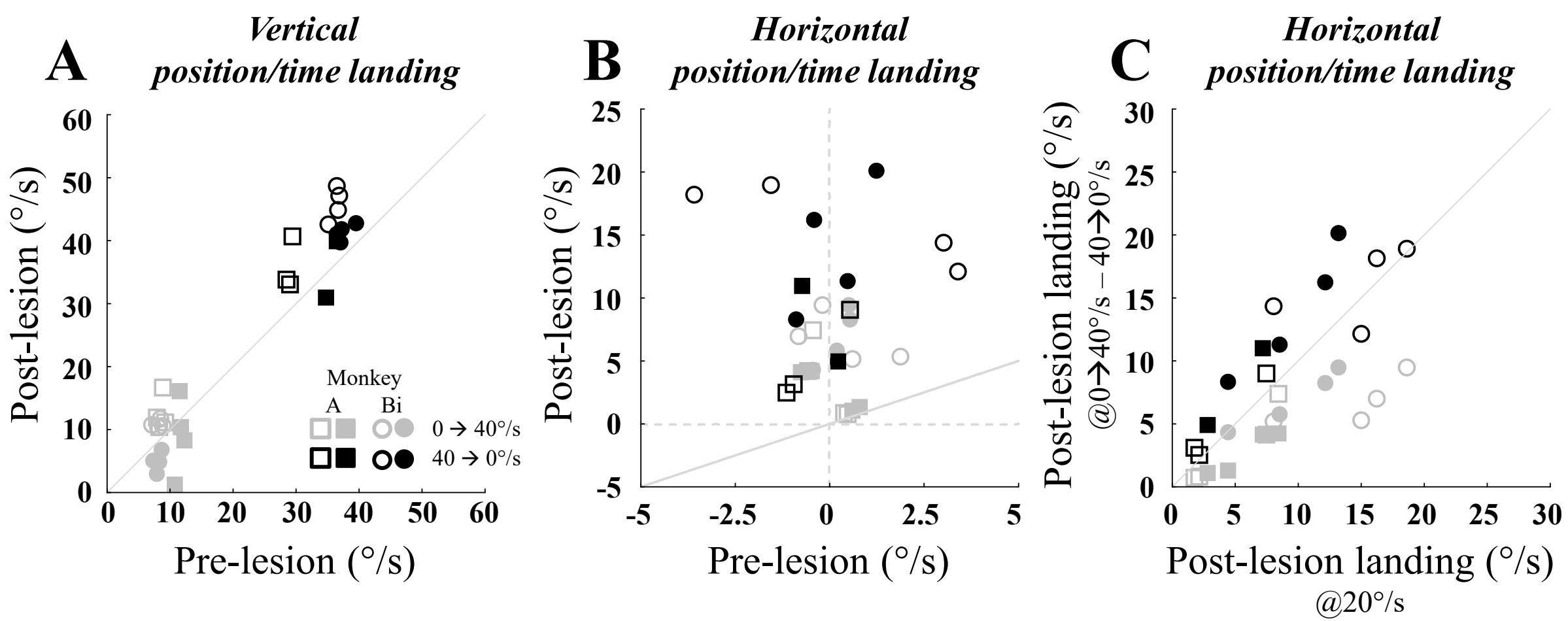
Fig. 8
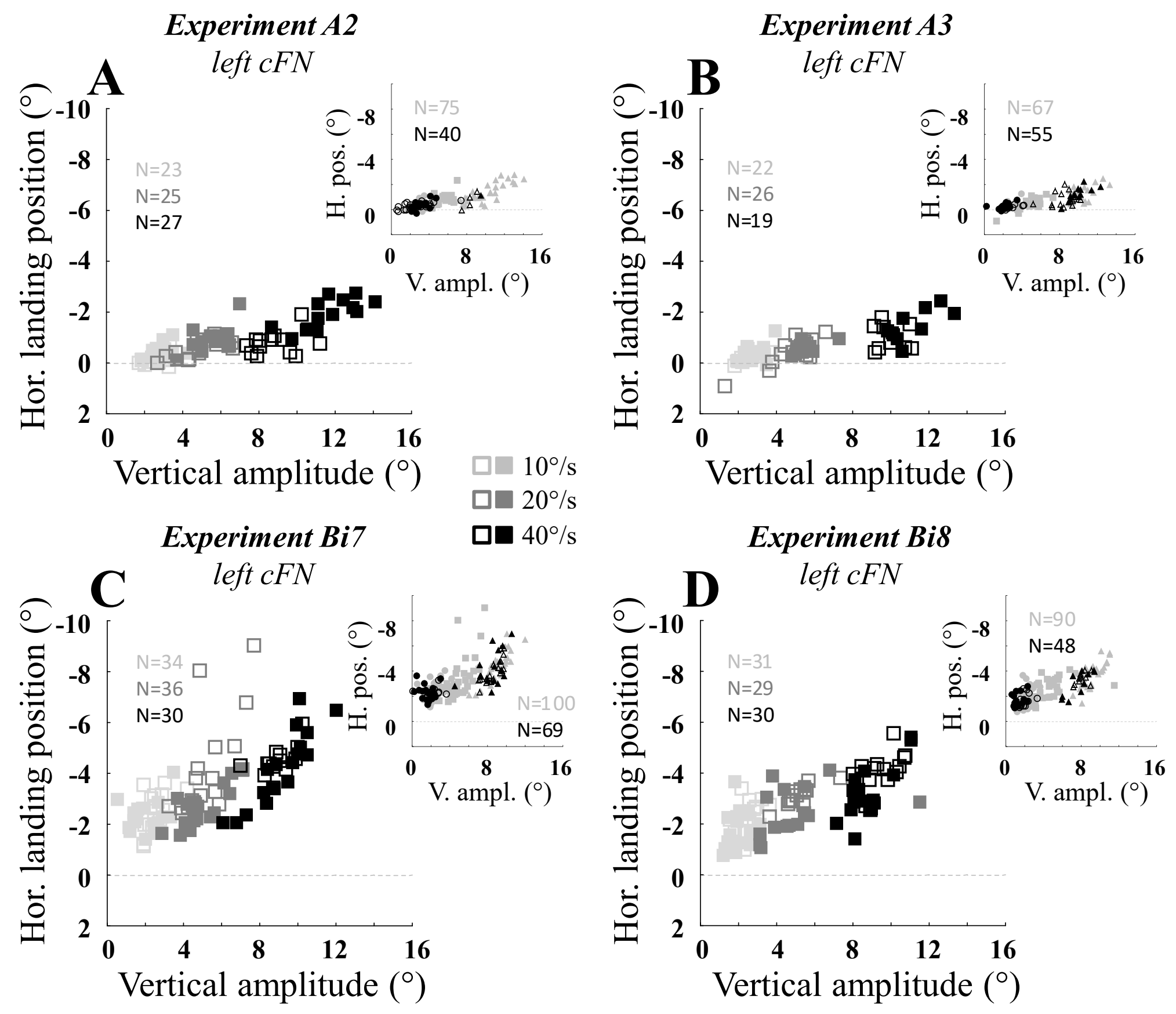
Figure 9

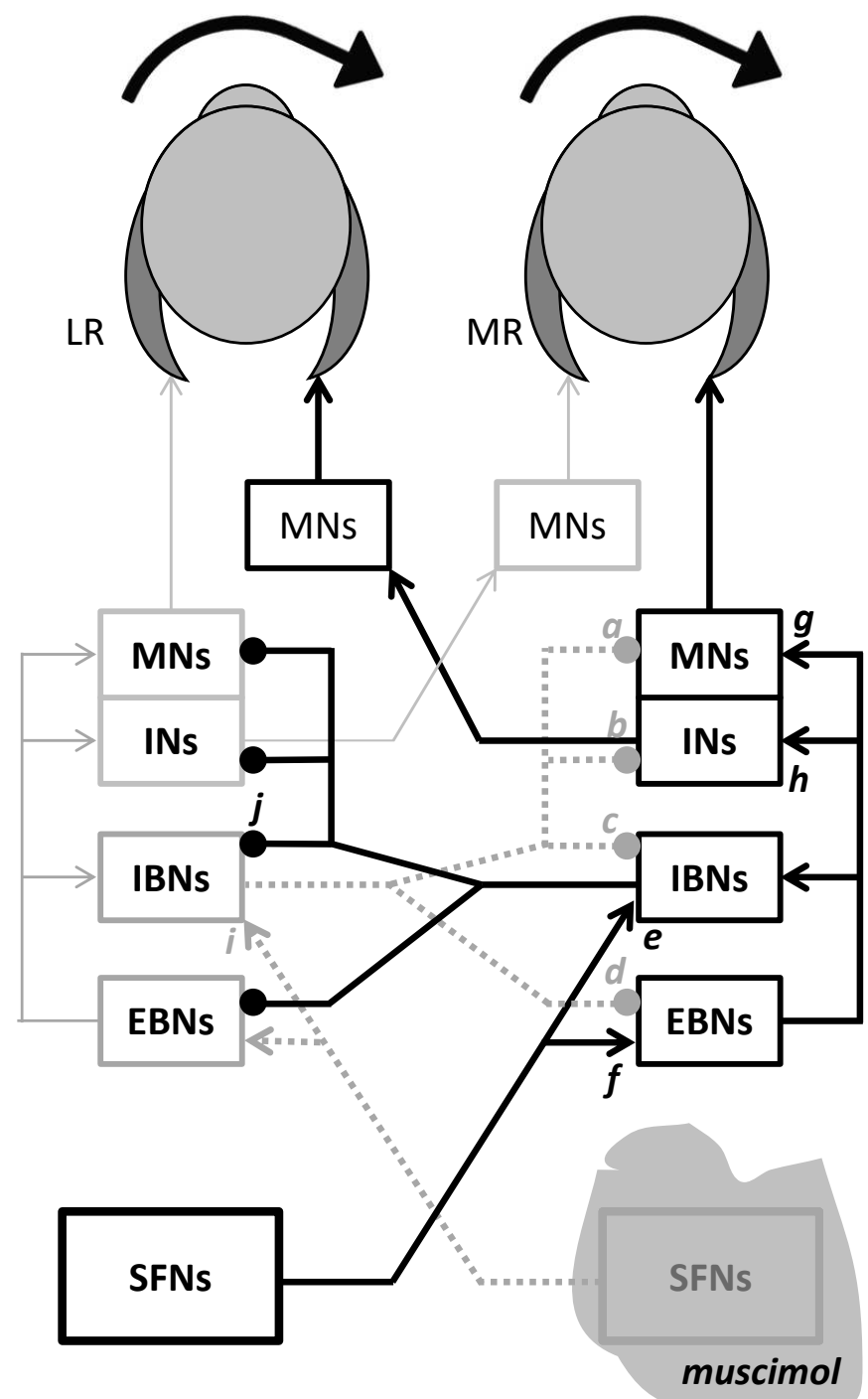


Table 1

\begin{tabular}{|c|c|c|c|c|c|c|c|c|c|c|c|c|c|c|}
\hline \multirow[b]{2}{*}{ Exp } & \multirow[b]{2}{*}{ injection } & & \multicolumn{4}{|c|}{$10 \% \mathrm{~s}$} & \multicolumn{4}{|c|}{$20 \% / \mathrm{s}$} & \multicolumn{4}{|c|}{$40^{\circ} / \mathrm{s}$} \\
\hline & & & $\mathrm{N}$ & Y-int & slope & $\mathrm{R}^{2}$ & $\mathrm{~N}$ & Y-int & slope & $R^{2}$ & $\mathrm{~N}$ & Y-int & slope & $R^{2}$ \\
\hline \multirow[t]{2}{*}{$\mathrm{A} 1$} & \multirow{2}{*}{$\begin{array}{l}\text { Left cFN } \\
1.0 \mu \mathrm{l}\end{array}$} & Amplitude & 18 & -0.2 & -0.108 & $0.09 \mathrm{NS}$ & 38 & -0.0 & -0.132 & $0.26 *$ & 20 & 1.1 & -0.239 & $0.48^{*}$ \\
\hline & & Duration & 18 & -0.5 & -0.001 & $0.001 \mathrm{NS}$ & 38 & 0.3 & -0.028 & $0.14 *$ & 20 & 1.6 & -0.067 & $0.52 *$ \\
\hline \multirow[t]{2}{*}{$A 2$} & \multirow{2}{*}{$\begin{array}{l}\text { Left cFN } \\
0.5 \mu \mathrm{l}\end{array}$} & Amplitude & 23 & 0.2 & -0.185 & $0.15 \mathrm{NS}$ & 25 & 0.7 & -0.281 & $0.42 *$ & 27 & 1.9 & -0.327 & $0.65^{*}$ \\
\hline & & Duration & 23 & -0.1 & -0.009 & $0.01 \mathrm{NS}$ & 25 & -0.2 & -0.014 & $0.07 \mathrm{NS}$ & 27 & 1.5 & -0.065 & $0.17^{*}$ \\
\hline \multirow[t]{2}{*}{ A3 } & \multirow{2}{*}{$\begin{array}{l}\text { Left cFN } \\
0.3 \mu \mathrm{l}\end{array}$} & Amplitude & 22 & 0.4 & -0.278 & $0.33^{*}$ & 26 & 1.1 & -0.328 & $0.66 *$ & 19 & 1.7 & -0.284 & $0.29 *$ \\
\hline & & Duration & 22 & 0.4 & -0.024 & $0.10 \mathrm{NS}$ & 26 & 0.6 & -0.031 & $0.06 \mathrm{NS}$ & 19 & -1.0 & -0.005 & $0.003 \mathrm{NS}$ \\
\hline \multirow[t]{2}{*}{ A4 } & \multirow{2}{*}{$\begin{array}{l}\text { Right cFN } \\
1.1 \mu \mathrm{l}\end{array}$} & Amplitude & 30 & 1.3 & 0.055 & $0.001 \mathrm{NS}$ & 26 & 2.4 & -0.062 & $0.003 \mathrm{NS}$ & - & - & - & - \\
\hline & & Duration & 30 & -0.9 & 0.070 & $0.08 \mathrm{NS}$ & 26 & 0.7 & 0.034 & $0.03 \mathrm{NS}$ & - & - & - & - \\
\hline \multirow[t]{2}{*}{ A5 } & \multirow{2}{*}{$\begin{array}{l}\text { Right cFN } \\
1.0 \mu \mathrm{l}\end{array}$} & Amplitude & 15 & 2.5 & -0.411 & $0.29 *$ & 28 & 1.5 & 0.044 & $0.00 \mathrm{NS}$ & 18 & 5.7 & -0.413 & $0.31 *$ \\
\hline & & Duration & 15 & 3.1 & -0.069 & $0.10 \mathrm{NS}$ & 28 & 1.5 & 0.005 & $0.00 \mathrm{NS}$ & 18 & 1.9 & -0.007 & $0.002 \mathrm{NS}$ \\
\hline \multirow[t]{2}{*}{$A 6$} & \multirow{2}{*}{$\begin{array}{l}\text { Right cFN } \\
0.5 \mu \mathrm{l}\end{array}$} & Amplitude & 26 & 0.6 & 0.252 & $0.18^{*}$ & 24 & 0.5 & 0.207 & $0.26 *$ & 26 & -0.1 & 0.312 & 0.53* \\
\hline & & Duration & 26 & 0.5 & 0.026 & $0.13 \mathrm{NS}$ & 24 & 0.8 & 0.019 & $0.11 \mathrm{NS}$ & 26 & -0.1 & 0.066 & $0.36^{*}$ \\
\hline \multirow[t]{2}{*}{$\mathrm{Bi} 7$} & \multirow{2}{*}{$\begin{array}{l}\text { Left cFN } \\
0.2 \mu \mathrm{l}\end{array}$} & Amplitude & 34 & -1.6 & -0.355 & $0.15^{*}$ & 36 & 1.0 & -0.889 & $0.41 *$ & 30 & 2.6 & -0.772 & $0.67^{*}$ \\
\hline & & Duration & 34 & -0.5 & -0.078 & $0.28 *$ & 36 & 3.2 & -0.198 & $0.37 *$ & 30 & -1.8 & -0.066 & $0.09 \mathrm{NS}$ \\
\hline \multirow[t]{2}{*}{$\mathrm{Bi} 8$} & \multirow{2}{*}{$\begin{array}{l}\text { Left cFN } \\
0.2 \mu \mathrm{l}\end{array}$} & Amplitude & 31 & -0.9 & -0.522 & $0.18 *$ & 29 & -1.7 & -0.209 & $0.18^{*}$ & 30 & 2.7 & -0.701 & $0.56^{*}$ \\
\hline & & Duration & 31 & 0.1 & -0.088 & $0.30 *$ & 29 & -0.5 & -0.073 & $0.28 *$ & 30 & -0.6 & -0.078 & $0.14^{*}$ \\
\hline \multirow[t]{2}{*}{ Bi9 } & \multirow{2}{*}{$\begin{array}{l}\text { Right cFN } \\
0.5 \mu \mathrm{l}\end{array}$} & Amplitude & 24 & 0.8 & 0.338 & $0.22 *$ & 26 & -0.2 & 0.576 & $0.34 *$ & 24 & 3.1 & 0.061 & $0.00 \mathrm{NS}$ \\
\hline & & Duration & 24 & 1.0 & 0.021 & $0.07 \mathrm{NS}$ & 26 & -0.3 & 0.081 & $0.11 \mathrm{NS}$ & 24 & 3.4 & 0.006 & $0.00 \mathrm{NS}$ \\
\hline \multirow[t]{2}{*}{ Bi10 } & \multirow{2}{*}{$\begin{array}{l}\text { Right cFN } \\
0.2 \mu \mathrm{l}\end{array}$} & Amplitude & 28 & 1.3 & -0.130 & $0.02 \mathrm{NS}$ & 28 & -0.3 & 0.351 & $0.23 *$ & 26 & 0.8 & 0.120 & $0.02 \mathrm{NS}$ \\
\hline & & Duration & 28 & 0.5 & 0.023 & $0.06 \mathrm{NS}$ & 28 & 0.7 & 0.013 & $0.01 \mathrm{NS}$ & 26 & 2.0 & -0.005 & $0.00 \mathrm{NS}$ \\
\hline
\end{tabular}


Table 2

\begin{tabular}{|c|c|c|c|c|c|c|c|c|c|c|}
\hline \multirow{2}{*}{ Exp } & \multirow[b]{2}{*}{ injection } & & \multicolumn{4}{|c|}{ Accelerating target } & \multicolumn{4}{|c|}{ Decelerating target } \\
\hline & & & $\mathrm{N}$ & Y-int & slope & $\mathrm{R}^{2}$ & $\mathrm{~N}$ & Y-int & slope & $\mathrm{R}^{2}$ \\
\hline \multirow[t]{2}{*}{$\mathrm{A} 2$} & \multirow{2}{*}{$\begin{array}{l}\text { Left cFN } \\
0.5 \mu \mathrm{l}\end{array}$} & Amplitude & 35 & 0.0 & -0.131 & $0.34^{*}$ & 5 & 4.9 & -0.663 & $0.74 \mathrm{NS}$ \\
\hline & & Duration & 35 & 0.0 & -0.012 & $0.06 \mathrm{NS}$ & 5 & -0.8 & 0.001 & $0.00 \mathrm{NS}$ \\
\hline \multirow[t]{2}{*}{ A3 } & \multirow{2}{*}{$\begin{array}{l}\text { Left cFN } \\
0.3 \mu \mathrm{l}\end{array}$} & Amplitude & 28 & -0.0 & -0.104 & $0.18^{*}$ & 27 & 1.1 & -0.233 & $0.31 *$ \\
\hline & & Duration & 28 & 0.2 & -0.016 & $0.15^{*}$ & 27 & -0.5 & -0.012 & $0.04 \mathrm{NS}$ \\
\hline \multirow[t]{2}{*}{ A4 } & \multirow{2}{*}{$\begin{array}{l}\text { Right cFN } \\
1.1 \mu \mathrm{l}\end{array}$} & Amplitude & 15 & 2.7 & -0.196 & $0.10 \mathrm{NS}$ & - & - & - & - \\
\hline & & Duration & 15 & 3.1 & -0.034 & $0.06 \mathrm{NS}$ & - & - & - & - \\
\hline \multirow[t]{2}{*}{ A6 } & \multirow{2}{*}{$\begin{array}{l}\text { Right cFN } \\
0.5 \mu \mathrm{l}\end{array}$} & Amplitude & 24 & 0.7 & 0.215 & $0.29 *$ & 27 & 0.4 & 0.231 & $0.39 *$ \\
\hline & & Duration & 24 & 0.4 & 0.026 & $0.14 \mathrm{NS}$ & 27 & 1.1 & 0.027 & $0.14 \mathrm{NS}$ \\
\hline \multirow[t]{2}{*}{$\mathrm{Bi7}$} & \multirow{2}{*}{$\begin{array}{l}\text { Left cFN } \\
0.2 \mu \mathrm{l}\end{array}$} & Amplitude & 35 & -2.3 & 0.016 & $0.00 \mathrm{NS}$ & 34 & 0.9 & -0.581 & $0.34^{*}$ \\
\hline & & Duration & 35 & -1.8 & -0.019 & $0.04 \mathrm{NS}$ & 34 & -0.7 & -0.088 & $0.25^{*}$ \\
\hline \multirow[t]{2}{*}{$\mathrm{Bi} 8$} & \multirow{2}{*}{$\begin{array}{l}\text { Left cFN } \\
0.2 \mu \mathrm{l}\end{array}$} & Amplitude & 26 & -1.4 & -0.205 & $0.06 \mathrm{NS}$ & 22 & 1.5 & -0.594 & $0.55^{*}$ \\
\hline & & Duration & 26 & -0.4 & -0.063 & $0.32^{*}$ & 22 & -1.3 & -0.052 & $0.10 \mathrm{NS}$ \\
\hline \multirow[t]{2}{*}{ Bi9 } & \multirow{2}{*}{$\begin{array}{l}\text { Right cFN } \\
0.5 \mu \mathrm{l}\end{array}$} & Amplitude & 28 & 1.0 & 0.013 & $0.00 \mathrm{NS}$ & 25 & -0.3 & 0.310 & $0.33^{*}$ \\
\hline & & Duration & 28 & 1.0 & 0.002 & $0.00 \mathrm{NS}$ & 25 & 0.7 & 0.039 & $0.17^{*}$ \\
\hline \multirow[t]{2}{*}{ Bi10 } & \multirow{2}{*}{$\begin{array}{l}\text { Right cFN } \\
0.2 \mu \mathrm{l}\end{array}$} & Amplitude & 29 & 0.9 & 0.115 & $0.04 \mathrm{NS}$ & 22 & -2.2 & 0.537 & $0.12^{*}$ \\
\hline & & Duration & 29 & 0.7 & 0.016 & $0.04 \mathrm{NS}$ & 22 & 3.7 & -0.04 & $0.05 \mathrm{NS}$ \\
\hline
\end{tabular}

